\title{
Suppression of Hepcidin Expression and Iron Overload Mediate Salmonella Susceptibility in Ankyrin 1 ENU- Induced Mutant
}

\author{
Kyoko E. Yuki ${ }^{1,3}$, Megan M. Eva ${ }^{1,3}$, Etienne Richer ${ }^{1,3}$, Dudley Chung ${ }^{5}$, Marilène Paquet ${ }^{4}$, Mathieu Cellier ${ }^{6}$, \\ François Canonne-Hergaux ${ }^{7,9,10}$, Sophie Vaulont ${ }^{8}$, Silvia M. Vidal ${ }^{1,3}$, Danielle Malo ${ }^{1,2,3 *}$ \\ 1 Department of Human Genetics, McGill University, Montréal, Quebec, Canada, 2 Department of Medicine, McGill University, Montréal, Quebec, Canada, 3 Complex Traits \\ Group of the McGill Life Sciences Complex, McGill University, Montréal, Quebec, Canada, 4 Comparative Medicine and Animal Resources Centre, McGill University, \\ Montréal, Quebec, Canada, 5 Department of Biochemistry and Microbiology, University of Victoria, Victoria, British Columbia, Canada, 6 Centre INRS-Institut Armand \\ Frappier, Laval, Quebec, Canada, 7 INSERM U1043-CPTP, Toulouse, France, 8 INSERM, U1016, Institut Cochin, Paris, France, 9 CNRS, U5282, Toulouse, France, 10 Université \\ de Toulouse, UPS, Centre de Physiopathologie de Toulouse Purpan (CPTP), Toulouse, France
}

\begin{abstract}
Salmonella, a ubiquitous Gram-negative intracellular bacterium, is a food borne pathogen that infects a broad range of hosts. Infection with Salmonella Typhimurium in mice is a broadly recognized experimental model resembling typhoid fever in humans. Using a $N$-ethyl- $N$-nitrosurea (ENU) mutagenesis recessive screen, we report the identification of Ity 16 (Immunity to Typhimurium locus 16), a locus responsible for increased susceptibility to infection. The position of Ity16 was refined on chromosome 8 and a nonsense mutation was identified in the ankyrin 1 (Ank1) gene. ANK1 plays an important role in the formation and stabilization of the red cell cytoskeleton. The Ank $1^{\text {tty } 16 / 1 \text { ty } 16}$ mutation causes severe hemolytic anemia in uninfected mice resulting in splenomegaly, hyperbilirubinemia, jaundice, extramedullary erythropoiesis and iron overload in liver and kidneys. Ank $7^{\text {ty } 16 / \text { /ty } 16}$ mutant mice demonstrated low levels of hepcidin (Hamp) expression and significant increases in the expression of the growth differentiation factor 15 (Gdf15), erythropoietin (Epo) and heme oxygenase 1 (Hmox1) exacerbating extramedullary erythropoiesis, tissue iron deposition and splenomegaly. As the infection progresses in Ank $1^{1 t y 16 / 1 t y 16}$, the anemia worsens and bacterial load were high in liver and kidneys compared to wild type mice. Heterozygous $A n k 1^{+/ l t y 16}$ mice were also more susceptible to Salmonella infection although to a lesser extent than Ank $1^{1 t y 16 /}$ ${ }_{1 t y} 16$ and they did not inherently present anemia and splenomegaly. During infection, iron accumulated in the kidneys of $A n k 1^{+/ l t y 16}$ mice where bacterial loads were high compared to littermate controls. The critical role of HAMP in the host response to Salmonella infection was validated by showing increased susceptibility to infection in Hamp-deficient mice and significant survival benefits in Ank $1^{+/ l t y 16}$ heterozygous mice treated with HAMP peptide. This study illustrates that the regulation of Hamp and iron balance are crucial in the host response to Salmonella infection in Ank1 mutants.
\end{abstract}

Citation: Yuki KE, Eva MM, Richer E, Chung D, Paquet M, et al. (2013) Suppression of Hepcidin Expression and Iron Overload Mediate Salmonella Susceptibility in Ankyrin 1 ENU-Induced Mutant. PLoS ONE 8(2): e55331. doi:10.1371/journal.pone.0055331

Editor: Dipshikha Chakravortty, Indian Institute of Science, India

Received October 10, 2012; Accepted December 20, 2012; Published February 4, 2013

Copyright: (C) 2013 Yuki et al. This is an open-access article distributed under the terms of the Creative Commons Attribution License, which permits unrestricted use, distribution, and reproduction in any medium, provided the original author and source are credited.

Funding: This work was supported by the Team Program of the Canadian Institutes of Health Research (CTP-87520) to DM and SMV. The funders had no role in study design, data collection and analysis, decision to publish, or preparation of the manuscript. KEY was a recipient of a Faculty of Medicine Internal Studentship Award and MME was a recipient of a Research Institute of the MUHC Studentship. SMV holds a Canada Research Chair and DM is a McGill Dawson Scholar.

Competing Interests: The authors have declared that no competing interests exist.

*E-mail: danielle.malo@mcgill.ca

\section{Introduction}

Salmonella infections in humans are responsible for two major diseases, typhoid fever caused by Salmonella Typhi and Salmonella Paratyphi and a diarrheal disease known as salmonellosis caused by several non host specific serotypes including Salmonella Typhimurium and Salmonella Enteritidis. Typhoid is transmitted by a fecal-oral route through contaminated food and water and is endemic in areas of poor water sanitation. It is estimated by the World Health Organization that there are 21 million new cases of typhoid fever each year resulting in approximately 200,000 deaths. In addition, 1 to $5 \%$ of patients become asymptomatic chronic carriers serving as reservoirs from which new Salmonella Typhi infections can be transmitted [1]. Early during infection, phagocytes are instrumental in the control of bacterial replication through the production of pro-inflammatory cytokines such as
IFN $\gamma, T N F \alpha$ and IL-12. Immunocompromised patients due to chronic granulomatous disease (deficient in NADPH oxidase activity), defects in the IFN $\gamma$ or IL-12 signaling pathway or HIV infection are more susceptible to disseminated Salmonella infection $[2,3,4]$. In addition, patients with hemoglobinopathies resulting in iron overload such as sickle cell anemia and thalassemia present increased susceptibility to Salmonella infection $[5,6]$. In the mouse, Salmonella Typhimurium infection results in a systemic disease with clinical manifestations resembling those found in humans with typhoid fever. The severity of infection depends on a variety of factors including the dose of the inoculum, as well as the interaction of host and bacterial genetic determinants. Several strains of mice show varying degrees of susceptibility to Salmonella Typhimurium infection with the mouse strain 129 substrains showing the most resistance. The study of the natural variation of the host response to infection with Salmonella Typhimurium in 
spontaneous mouse mutants have identified important innate immune genes having Mendelian contribution to disease susceptibility and contributing to different mechanisms including pathogen recognition ( $\mathrm{Tlr} 4^{\mathrm{P} 712 \mathrm{H}}$ in $\mathrm{C} 3 \mathrm{H} / \mathrm{HeJ}$ ), phagosome transport of divalent cations including iron (Nrampl ${ }^{\text {G1 } 69 D}$ in C57BL/6J and BALB/cJ) or erythropoiesis and iron metabolism $\left(\mathrm{Pklr}^{\mathrm{I} 90 \mathrm{~N}}\right.$ in AcB61 mice) $[7,8,9,10]$.

Due to the limited amount of natural variation found in classical inbred mice, we have used $\mathcal{N}$-ethyl- $\mathcal{N}$-nitrosurea (ENU) mutagenesis to generate novel mutations responsible for increased susceptibility to Salmonella infection. Recessive ENU induced mutations are bred to homozygosity with the use of a threegeneration breeding scheme and challenged with Salmonella Typhimurium. In the current screen we have evaluated 216 pedigrees for their susceptibility to infection and identified 5 deviant pedigrees. In this paper, we report the identification of one of these ENU mutants named Ity 16 that carries a nonsense mutation in the gene Ank1. Ank1 encodes a red blood cell (RBC) adaptor protein consisting of three major functional domains: an N-terminal membrane binding, a spectrin binding and a Cterminal regulatory domain [11]. ANK1 plays an important role in RBC membrane stability by mediating the attachment of band 3 (SLC4A1) and protein 4.2 (EPB4.2) to the spectrin-based membrane cytoskeleton [12]. A number of mutations in murine Ank1, both spontaneous and ENU-induced, have been described to cause hemolytic anemia $[13,14,15,16,17]$. In humans, mutations within ANK1 cause hereditary spherocytosis, a disease characterized by hemolytic anemia $[18,19,20]$. In the current paper, we show that $A n k 1^{\text {Ity } 16 / \text { It } y 16}$ and $A n k 1^{+/ I t y 16}$ mice have increased susceptibility to Salmonella Typhimurium infection, although in the latter group the increased susceptibility is delayed and milder. The suppression of hepcidin (Hamp) expression and iron overload contribute to their increased susceptibility to Salmonella infection.

\section{Materials and Methods}

\section{Mice and ENU Mutagenesis}

All animal experiments were performed under conditions specified by the Canadian Council on Animal Care and the animal use protocol was approved by McGill University Facility Animal Care Committee. Generation 0 (G0) 129S1 males were mutagenized with a single injection of $150 \mathrm{mg}$ per $\mathrm{kg}$ of body weight of $\mathcal{N}$-ethyl- $\mathcal{N}$-nitrosurea (ENU) given intraperitoneally. G0 males were outcrossed to $129 \mathrm{X} 1$ females to create G1 progeny that were subsequently crossed to DBA/2J. Resulting G2 animals were intercrossed to produce the G3 mice that were phenotyped for their susceptibility to Salmonella infection. Hamp ${ }^{\text {tm1Svl }}$ knock out mice [21] were transferred onto a 129S6 background, a strain that carries a wild-type allele of Slc11a1 (129S6.B6*129S2-Hamp ${ }^{\mathrm{tm} 1 \mathrm{Svl}}$ ).

\section{Genotyping}

The genome scan was performed using a 1441 SNP panel (The Centre for Applied Genomics, Toronto, Ontario, Canada) on 22 mice. Additional genotyping was performed by microsatellite analysis or restriction enzyme digests of SNP markers. Sequencing of the Ankl gene was performed on cDNA isolated from spleens of $A n k 1^{\text {ty } 16 / I t y 16}$ and $A n k 1^{+/+}$mice using 3730xl DNA Analyzer (Applied Biosystems) from the McGill University and Genome Quebec Innovation Centre.

\section{In vivo Salmonella Infections}

Mice were infected with 5000 CFUs of Salmonella Typhimurium strain Keller as described by us previously [22]. The infectious inoculum was diluted to 25,000 CFUs per $\mathrm{mL}$ and $0.2 \mathrm{~mL}$ was injected into the caudal vein of 7 week old mice of both sexes. To determine CFUs in tissues, mice were euthanized with $\mathrm{CO}_{2}$ at day 2 and day 6 post infection and spleen, liver and kidney were removed aseptically, weighed and homogenized. Homogenates were diluted in saline and plated on trypticase soy agar (TSA) overnight. Other groups of mice were coinfected with 2500 CFUs of Salmonella Typhimurium strain Keller and 2500 CFUs of $\Delta$ tonB constructed by allelic exchange in serovar Keller [23]. The tissues were collected 2 days after infection and tissue homogenates were plated on TSA containing or not $50 \mathrm{mg} / \mathrm{ml}$ of kanamycin.

\section{Western Blots}

Erythrocyte ghost membranes were prepared by osmotic lysis as previously described ([15]). Primary antibody to detect ANK1 (N13) was purchased from Santa Cruz Biotechnology (SC-87552) and was used at a 1:200 dilution. This antibody was raised against a peptide sequence spanning exons 8 and 9 of the $A n k 1$ transcript (ENSMUST00000121802) and recognized the full length ANK1. The ACTIN antibody and the secondary antibodies for Western detection (anti-rabbit IgG) were purchased from Cell Signaling Technology.

\section{Hepcidin Treatment}

Mice were treated with $50 \mu \mathrm{g}$ of HAMP (Peptide International, Louisville KY) resuspended in $100 \mu \mathrm{l}$ of PBS intraperitoneally. Four hours later, mice were infected with 5000 CFUs of Salmonella Typhimurium and monitored for survival over a period of 14 days. Littermate controls were given $100 \mu \mathrm{l}$ of PBS intraperitoneally.

\section{Histology}

Tissues were collected from Ank1 $1^{\text {Ity } 16 / \text { Ity } 16}, A n k 1^{+/ \text {Ity } 16}$ and $A n k 1^{+/+}$mice and fixed in $10 \%$ neutral buffered formalin for 24 hours at $20^{\circ} \mathrm{C}$, then placed in $70 \%$ ethanol at $4^{\circ} \mathrm{C}$ before processing and embedding (Goodman Cancer Research Center histology facility, McGill University). Embedded tissues were sectioned and stained with hematoxylin and eosin or prussian blue.

\section{Hematologic and Biochemical Parameters}

Blood samples from $A n k 1^{\text {Ity } 16 / I_{1 y} 16}, A n k 1^{+/ I t y 16}$ and $A n k 1^{+/+}$mice were collected by cardiac puncture and analyzed for CBC \& differential and reticulocyte counts (Diagnostic Research Support Service, Comparative Medicine and Animal Resources Centre, McGill University). Serum was isolated with a serum separator tube (Sarstedt) and analyzed for bilirubin, blood urea nitrogen (BUN), alanine transaminase (ALT) and aspartate transaminase (AST) (Diagnostic Research Support Service, Animal Resources Centre, McGill University).

\section{QRT-PCR}

Total RNA was extracted from spleen, liver and kidneys with Trizol Reagent (InVitrogen, Burlington ON) according to manufacturer instructions. cDNAs were synthesized using SuperScript ${ }^{\circledR}$ II Reverse Transcriptase (InVitrogen). Quantitative PCR was performed on a Chromo4 (BioRad, Mississauga ON) or StepOnePlus (Applied Biosystem, Carlsbad CA) using SYBR Green (Applied Biosystems) for hepcidin (Hamp), ferroportin (Slc40a1), Il6, Il1, Ifng, erythropoietin (Epo), heme oxygenase 1 (Hmox l) and growth differentiation factor 15 (Gdf15) expression. Two housekeeping genes: Tbp (TATA box binding protein) and Hprt (hypoxanthine guanine phosphoribosyl transferase) were used. The relative expression of the genes was normalized to the amount of Tbp and Hprt (endogenous reference) and relative to 
a calibrator (untreated wild type genotype) for each tissue by using the comparative $2^{(- \text {Delta Delta } \mathrm{Ct})}$ method. The primer sequences are provided in Table $\mathrm{S} 1$.

\section{Statistical Analysis}

Data (unless otherwise specified) was analyzed by two-tailed Mann Whitney test and two-way ANOVA using GraphPad Prism 5. Data for qPCR was analyzed in R by ANOVA and Welch two sample t-test [24].

\section{Results}

\section{Identification of a Novel Salmonella Susceptibility Locus using ENU Chemical Mutagenesis}

The breeding scheme used to identify the Ity 16 pedigree is shown in Fig. 1A. Mutagenized 129S1 G0 males were crossed to wild-type 129X1 females to produce G1 males. These G1 males were crossed to DBA/2J females to generate G2 offspring that were randomly intercrossed to produce G3 progeny. G3 animals were phenotyped for susceptibility to Salmonella infection with 5,000 CFUs and monitored for a period of 14 days. Mortality in the Ity 16 pedigree was observed between day 3 post infection and continued until day 11 with $25 \%$ of mice succumbing to infection by day 6 (Fig. 1B). An initial genome scan was performed using twenty-two G3 animals (8 susceptible and 14 resistant mice) and 708 informative DNA markers. Binary analysis of the genome scan revealed a locus on chromosome 8 at position $25.8 \mathrm{Mb}$ with a LOD score of 3.72 (Fig. 1G). DNA samples used in the genome scan were also genotyped with DNA markers discriminating 129S1 and 129X1 genomes to ensure that mice were homozygous for the mutagenized 129 allele (data not shown). Fine mapping of the chromosome 8 region with 27 additional G3 animals and 9 markers reduced the region to a $2.5 \mathrm{Mb}$ region (Fig. 1D) that includes 23 annotated genes, 10 predicted genes and 2 miRNAs (MGI). The survival curves of the Ity 16 G3 mice were plotted according to their genotype at the peak marker (rs32874474) on chromosome 8 (Fig. 1E). All mice homozygous for the 129S1 allele succumbed to infection by day 6 . Mice carrying the DBA/2J alleles at this locus were $100 \%$ resistant to infection. Interestingly, mice with a heterozygous genotype at the peak marker had an intermediate survival phenotype, with mortality starting at day 7 (Fig. 1E).

\section{Ity16 Mutant Mice Present Severe Hemolytic Anemia that Worsened during Infection}

Compared to wild type and heterozygous littermates, mutant mice are characterized clinically by low body weight (Fig. 2A), pallor of mucosal linings and yellow discoloration of subcutaneous tissues, a consequence of increased levels of bile pigment (bilirubin) in the blood (Fig. 2B). In addition, these mutants exhibit impressive enlargement of the spleen, accounting for up to $10 \%$ of their body weight (Fig. 2C). This is accompanied by significant increases in kidney and heart weights (Fig. 2C). Hematological analysis of uninfected mutant Ity 16 mice showed they have severe constitutive anemia as demonstrated by low hematocrit levels (25\% in mutants compared to $50 \%$ in wildtype and heterozygous mice) which decreased to as low as $15 \% 2$ days after infection (Table 1). This decrease in hematocrit levels is mirrored by similar decreases in hemoglobin and red blood cell levels during infection (Table 1). Additionally, there were a higher percentage of circulating reticulocytes in the blood of mutants compared to both wild type and heterozygous littermates (Table 1). As a consequence of severe anemia, Ity16 mutant mice present extensive extramedullary erythropoiesis in the spleen and liver as assessed by histopathological examination that is associated in the spleen with severe lymphoid depletion (Fig. S1). Blood smear examination of mutant Ity 16 mice showed abnormally shaped red blood cells, marked anisocytosis, and reticulocytosis and the presence of spherocytes (data not shown). Total number of WBC, neutrophils and lymphocytes were significantly higher in Ity 16 mutant mice compared to littermate controls before and after infection (Table 1) after correcting for the high percentage of nucleated RBC (Table 1). The total number of neutrophils increased significantly during infection in all three groups although it was more pronounced in Ity 16 mutants.

\section{A Mutation within Ank1 is Responsible for Susceptibility of Ity16 Mice to Salmonella Infection}

Identification of the causative gene for Ity 16 focused on the region between $23.5 \mathrm{Mb}$ and $26 \mathrm{Mb}$ on mouse chromosome 8 . Genes involved in hematopoiesis and causing splenomegaly and anemia were of particular interest because of the distinct phenotype exhibited by the mutant mice. Only the gene ankyrin 1 (Ankl) met our criteria. ANK1 is primarily known for its structural role in erythrocytes. Ank1 is part of a small gene family which members are adaptor structural components linking lipid membranes to the cytoskeleton showing an essential role in the stability of plasma membranes of many cell types [25]. The Ank1 gene comprises a total of 44 exons. Several $A n k 1$ splice variants are observed and the full-length isoform encodes for a protein of 1907 amino acids $(200-210 \mathrm{kDa})$. Erythroid Ank1 consists of three major conserved domains including an N-terminal membranebinding domain, a spectrin-binding domain and a C-terminal regulatory domain containing a death domain motif [26,27]. Ity 16 mutant showed a $\mathrm{C}$ to $\mathrm{T}$ transition at cDNA position 4069 $($ c. $4069 \mathrm{C}>\mathrm{T})$ resulting in a nonsense mutation in exon 33 at amino acid position 1357 (p.Gln1357Ter ) (Fig. 3A). This premature stop codon results in a predicted truncation of the ANK1 protein by 550 amino acids with the loss of the C-terminal regulatory and the death domains but retaining the membranebinding and most of the spectrin-binding domains (Fig. 3B). Immunoblotting analysis of fractioned erythrocyte membrane ghosts revealed that the non-sense mutation abrogated ANK1 protein expression in Ity 16 mutant mice (Fig. 3C). A truncated form of the protein (calculated molecular weigth of $144 \mathrm{kDa}$ ) could not be detected suggesting that the abnormal protein is targeted for degradation. The frequency of adult mice (older than 4 weeks) on a 129S1/DBA2J hybrid background with a c.4069C $>$ T genotype was not in Hardy-Weinberg equilibrium: we obtained a ratio that was significantly different $(p=.04)$ from the expected 1-2-1 ratio for a cross between mice heterozygous $(+/ \mathrm{m})$ for the mutation. Genotype frequencies in 249 animals were $29 \%$ for wild type mice, $52 \%$ for heterozygous and $18 \%$ for homozygous mutants.

\section{Iron Overload in Ank $1^{\text {Ity } 16 / \text { lty } 16}$ Mutant Mice Facilitates Proliferation of Salmonella in Liver and Kidneys}

Increased amounts of iron pigment deposition were detected in Ank1 $1^{1 \text { ty } 16 / 1 \text { ty } 16}$ mutant livers and kidneys (Prussian blue positive pigment) compared with wild type and heterozygous littermates in non-infected conditions and in mice at 2 days after infection (Fig. $\mathrm{S} 1)$. Iron accumulates predominantly in the hepatocytes and in the cytoplasm of the epithelium of the renal tubules. The high levels of iron in the liver and kidneys of $A n k 1^{1 \text { ty } 16 / \text { Ity } 16}$ mutant mice suggest that the rapid turnover of $\mathrm{RBC}$ in these mice leads to accumulation of iron in the liver and kidneys (secondary hemochromatosis). In contrast, splenic iron content was markedly 
A

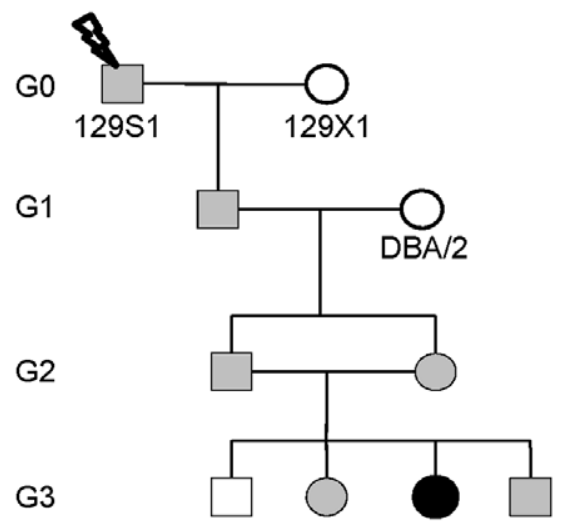

B

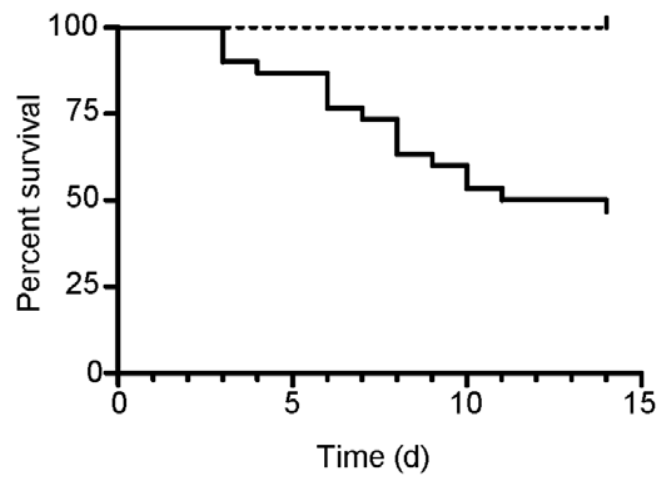

C

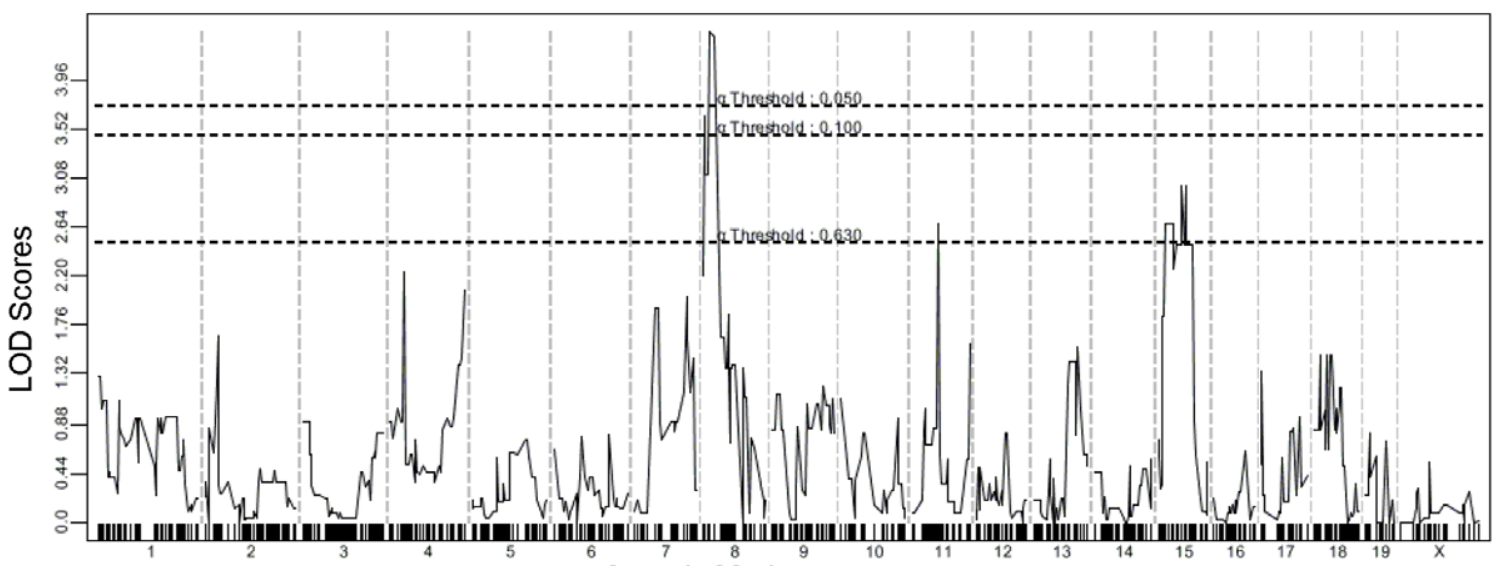

Genetic Markers

D

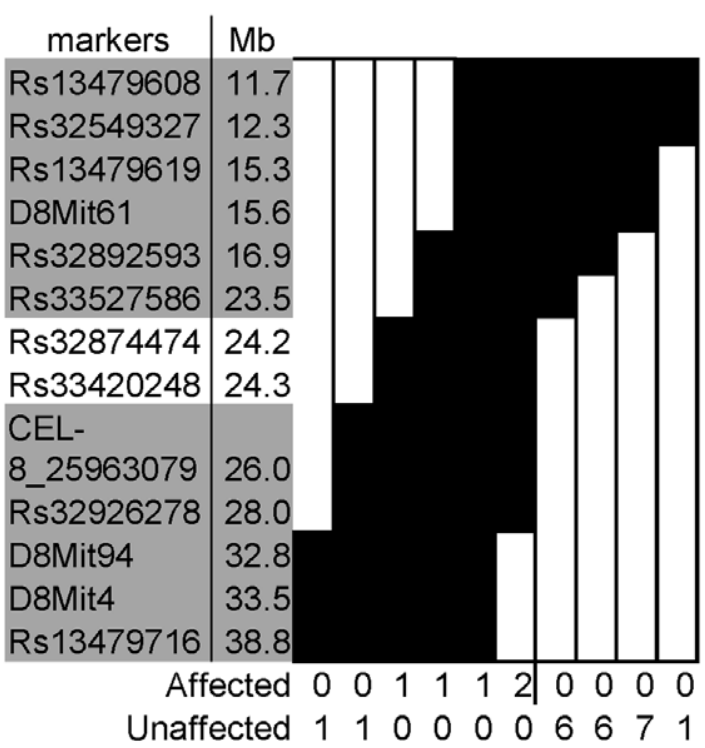

E

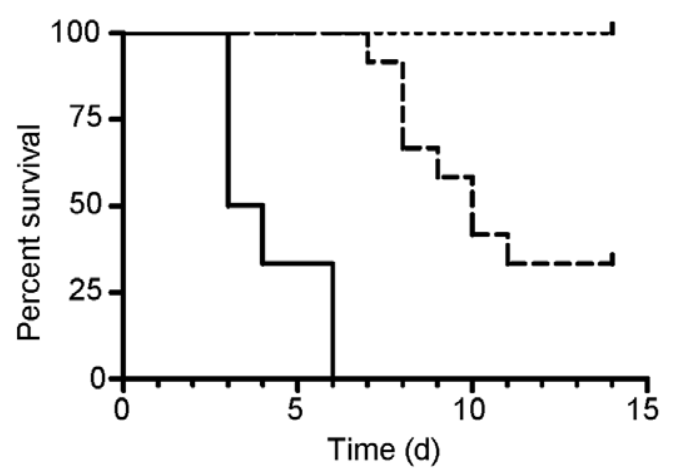

Figure 1. Identification and mapping of the Ity16 pedigree. A) Breeding scheme used to identify and map the mutant family. Females and males are represented by circles and squares respectively with black representing the homozygous mutant alleles, gray representing the heterozygous alleles, and white representing the wild type alleles. B) Survival curve of the G3 mice from the Ity 16 pedigree is represented by the solid line $(n=30)$ while wild type 129S1 $(n=5)$ mice are represented by dotted lines. Log-Rank (Mantel-Cox) $p=0.01$. C) Linkage analysis in 8 Salmonellasusceptible and 14 Salmonella-resistant mice identifies a significant peak on chromosome 8 . D) Fine mapping of the Ity 16 locus to a $2.5 \mathrm{Mb}$ region on chromosome 8. Black fill represents homozygous $129 \mathrm{~S} 1$ allele. White fill represents heterozygous or homozygous DBA/2 genotypes. E) Survival curves of Ity 16 mice according to their genotypes at peak marker on chromosome 8. Solid line represents homozygous 129S1 alleles ( $n=6)$, dashed line represents heterozygous $(n=12)$, and dotted line represents homozygous DBA/2 alleles $(n=12)$. Log-Rank (Mantel-Cox) for $A n k 1^{+/+}$and $A n k 1^{\text {tty } 16 / \text { tty } 16}$ $\mathrm{p}<0.0001, A n k 1^{+/+}$and $A n k 1^{+/ t y 16} \mathrm{p}=0.001$.

doi:10.1371/journal.pone.0055331.g001 
A

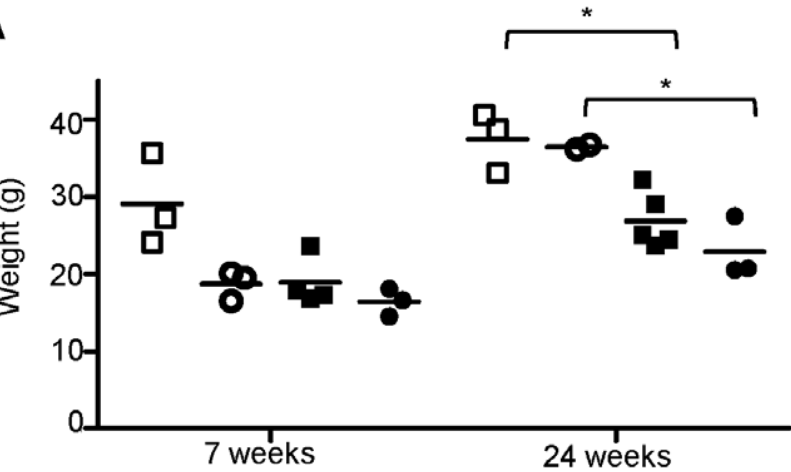

B

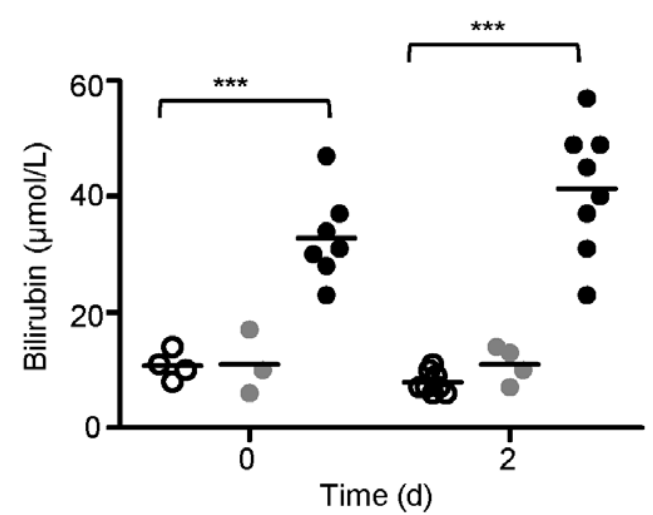

C

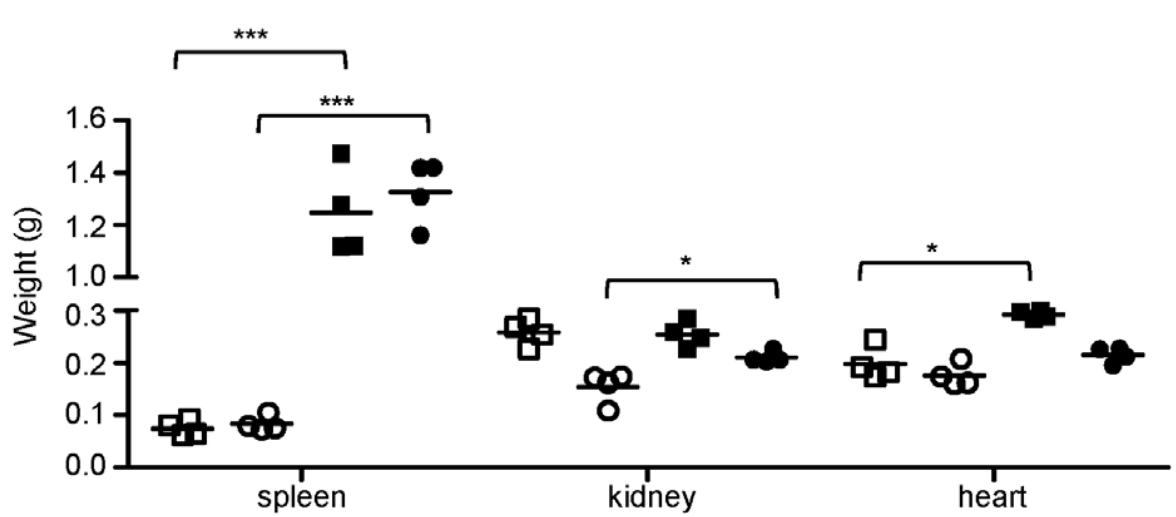

Figure 2. Ity16 mutant mice present massive splenomegaly, moderate increase in kidneys and heart weights and bilirubinemia. A) Body weight of wild type littermates and Ity 16 mice by sex (males are represented by squares, females by circles) at 7 weeks (open and black fill) and 24 weeks (open and black fill) $n=3$ per sex and genotype. B) Serum bilirubin levels were measured at day 0 and day 2 post infection in wild type (open circle), heterozygous (gray circle) and Ity 16 mutant (black circle) mice. C) Increased spleen, kidney and heart weights in Ity 16 mutant (black fill) mice compared to wild type littermates (open fill). The data are presented by sex (males are squares, females are circles). Results are representative of at least two experiments. An * represents a P-value of less than $0.05 ;{ }^{* *}$ represents a P-value of less than $0.001 ;{ }^{* * *}$ represents a P-value of less than 0.0001 .

doi:10.1371/journal.pone.0055331.g002

decreased in Ank1 $1^{\text {Ity } 16 / \text { Ity } 16}$ mutant mice compared to wild type littermates (Fig. S1). In Ank1 ${ }^{1 \text { ty } 16 / \text { Ity } 16}$ mutant mice, iron overload is associated with increased bacterial proliferation in the liver and kidneys. In infected mice, there was a gradation of microabcesses present in the liver that worsened with genotype but was not influenced by the age at the time of infection (Fig. S2). In addition, significant higher bacterial loads were observed in the liver (30100 times higher) and kidneys (10 times higher) of Ank1 1 ty 16/Ity 16 mutant compared to wild type and heterozygous littermates 2 days post infection (Fig. 4B and 4C). Because of the high bacterial burden present in the liver and kidney, biochemical measures of hepatic (alanine transaminase, ALT and aspartate transaminase, AST) and kidney function (blood urea nitrogen, BUN) were evaluated before and after infection. ALT and AST were elevated after infection only in Ank $1^{1 \text { ty } 16 / 1 \text { thy } 16}$ mutant mice (Fig. 5A and 5B) whereas BUN levels were significantly higher in uninfected and infected $A n k 1^{1 \text { ty } 16 / I_{1 y} 16}$ mice compared to controls (Fig. 5C). These data may indicate the presence of abnormal organ function in naïve Ank1 $1^{1 \text { ty 16/Ity 16 }}$ mice (kidney) and during infection (liver and kidney). In fact, we observed glomeruli with enlarged mesangium in Ank $1^{1 \text { ty } 16 / I t y 16}$ mice, a pathological change that may be compatible with membranoproliferative glomerulonephritis (Fig. S2). 
Table 1. Hematologic parameters in Ity16 mutant, heterozygous and wild type mice before (day 0 ) and after (day 2 ) infection with Salmonella Typhimurium.

\begin{tabular}{|c|c|c|c|c|c|c|}
\hline \multirow[b]{2}{*}{ Genotype } & \multicolumn{3}{|l|}{ Day 0} & \multicolumn{3}{|l|}{ Day 2} \\
\hline & Wt & Het & Ity16 & Wt & Het & Ity16 \\
\hline Hematocrit L/L & $0.523 \pm 0.007$ & $0.549 \pm 0.017$ & $0.252 \pm 0.013^{*}$ & $0.519 \pm 0.011$ & $0.526 \pm 0.023$ & $0.190 \pm 0020^{*}$ \\
\hline Hemoglobin $\mathrm{g} / \mathrm{L}$ & $167 \pm 0.88$ & $169 \pm 5.57$ & $76.9 \pm 4.02^{*}$ & $164 \pm 3.26$ & $165 \pm 7.22$ & $57.5 \pm 6.17^{*}$ \\
\hline $\mathrm{RBCs} \times 10^{12} / \mathrm{L}$ & $11.5 \pm 0.39$ & $13.2 \pm 0.21$ & $5.47 \pm 0.25^{*}$ & $10.7 \pm 0.23$ & $11.9 \pm 0.48$ & $3.98 \pm 0.39^{* \#}$ \\
\hline WBCs $\times 10^{9} / \mathrm{L}$ & $10.76 \pm 2.92$ & $9.73 \pm 1.64$ & $35 \pm 5.07$ & $9.85 \pm 0.65$ & $11.13 \pm 1.73$ & $22.92 \pm 3.01^{*}$ \\
\hline$\%$ reticulocytes & $5.1 \pm 0.17$ & $5.03 \pm 0.64$ & $44.9 \pm 7.68^{*}$ & $4.7 \pm 0.42$ & $5.1 \pm 1.36$ & $33.1 \pm 5.60^{*}$ \\
\hline neutrophils $\times 10^{9} / \mathrm{L}$ & $1.17 \pm 0.38$ & $0.86 \pm 0.12$ & $2.36 \pm 0.99$ & $2.08 \pm 0.25$ & $2.55 \pm 0.38$ & $7.54 \pm 0.98^{*}$ \\
\hline lymphocytes $\times 10^{9} / \mathrm{L}$ & $9.54 \pm 2.6$ & $8.82 \pm 1.57$ & $32.24 \pm 4.59^{*}$ & $7.54 \pm 0.52$ & $8.54 \pm 1.50$ & $14.88 \pm 2.71^{*}$ \\
\hline Nucleated RBCs/100 WBCs & 0 & $2.33 \pm 1.20$ & $66.86 \pm 11.15^{*}$ & $3.38 \pm 1.74$ & $3 \pm 3$ & $77 \pm 5.58^{*}$ \\
\hline
\end{tabular}

Wt : wild-type; Het : heterozygous.

* $p$ values $<0.05$ compared to wild type values of the same infection status.

${ }^{\#} \mathrm{p}$ values $<0.05$ compared to day 0 of the same genotype.

doi:10.1371/journal.pone.0055331.t001

To examine if iron accumulation in tissues has an impact on the bacterial load phenotype in $A n k 1^{\text {Ity } 16 / \text { Ity } 16}$ mutant mice, we infected mice with $\Delta \operatorname{ton} B$ Salmonella Typhimurium. The $\operatorname{ton} B$ mutation is known to inactivate several siderophore-dependent $\mathrm{Fe}^{3+}$ uptake systems in Salmonella and $\Delta \operatorname{tonB}$ Salmonella are as virulent as the wild-type strain in Slc11a1-deficient mice [23]. In the spleen where there is no iron accumulation, there was no significant genotype difference for the proliferation of $\Delta$ tonB and wild-type Salmonella (Fig. 4D). In contrast, the levels of both $\Delta \operatorname{ton} B$ and wild-type bacteria were significantly higher (by a factor of $\sim 2 \mathrm{Log}$ ) in the liver of mutant mice where there is iron overload (Fig. 4E). At this early time point, there was no iron accumulation in the liver of heterozygous mice (Fig. S1) and the mice were able to control bacterial growth as well as wild-type mice (Fig. 4E). The growth of $\Delta \operatorname{ton} B$ Salmonella appears to be affected by the presence of iron in the cellular microenvironment, suggesting that iron uptake via tonB is not limiting when iron is abundant in tissue. Overall, these data support the observation that tissue iron overload in $A n k 1^{1 t y 16 /}$ ${ }^{1 t y} 16$ mutant promotes Salmonella growth.

\section{Increased Expression of Epo and Gdf15 Paralleled Low Levels of Hamp Expression in Ank $1^{\text {Ity } 16 / \text { lty } 16}$ Mice}

Because of the severe iron overload present in the liver and kidney of Ank1 $1^{\text {Ity 16/ity16 }}$ mice, the expression of key genes involved in iron metabolism including hepcidin (Hamp), ferroportin (Slc40a1) and heme oxygenase 1 (Hmox1) and regulators of Hamp expression (Epo, Gdf15, Il1 and Il6) were investigated (Fig. 6 and 7). The liver is a major site of iron storage and in clinical conditions of iron overload, the liver become a major site of iron deposition. The kidneys have been shown also to play a role in iron homeostasis and to express both HAMP and SLC40Al $[28,29,30]$. In Ank1 $1^{\text {Ity } 16 / \text { Ity } 16}$ mice, the liver and the kidneys are major site for Salmonella replication and growth during infection. The expression of Hamp in both uninfected and infected Ity 16 mutant mice was significantly downregulated in the liver and kidneys compared to wild type littermates (Fig. 6A). On the other hand, the liver and kidney expression of the membrane iron exporter, Slc40a1 and Hmox 1 was significantly higher in Ank1 $1^{\text {Ity } 16 /}$ ${ }^{I}{ }^{16}$ mice at day 0 and day 2 post infection compared to $A n k 1^{+/+}$ (Fig. 6C and 7G). In the spleen of Ank1 $1^{1 \text { ty } 16 / \text { ity } 16}$ mutant mice, Slc40a1 and Hmox1 mRNA levels were significantly lower compared to wild-type littermates (Fig. 6C and 7C). In Ank1 ${ }^{1 \text { ty } 16 /}$
${ }^{I t y} 16$ mice, low Hamp expression had only a modest impact on the expression of liver Slc40al both at the mRNA (Fig. 6C) and protein levels (data not shown). We investigated the expression of two inhibitory erythroid regulators of Hamp expression, erythropoietin (Epo) (Fig. 6B) and growth differentiation factor 15 (Gdf15) (Fig. 6D). These analyses revealed a major significant increase in the expression of both Epo and Gdf15 only in Ank $1^{\text {Ity } 16 / i t y 16}$ mutant mice that could explain, at least in part, the low Hamp expression levels observed in these mice. During infection, the levels of $G d f 15$ were significantly more elevated in Ank $1^{\text {Ity } 16 / i t y 16}$ mutant mice compared to wild type littermates (Fig. 6D). In addition, cytokine mRNA levels (Ill, and Il6) known to be upregulated during Salmonella infection and to impact on Hamp transcription were measured (Fig. 7A-B). The spleen of Ank1 $1^{\text {Ity } 16 / \text { ity } 16}$ mutant mice appeared to be underresponsive to infection-induced cytokines as measured by very little or no induction of $I l 1$ and $I l 6$ (Fig. 7A-B). In the liver and the kidneys, the situation is different and $A n k 1^{1 t y 16}$; ${ }^{i t y} 16$ mice showed marked increases in $I l 1$ (liver and kidneys) and Il6 (liver) mRNA expression during infection (Fig. 7A). In these two tissues, high levels of $I l 1$ and $I l 6$ cytokines did not promote Hamp transcription in Ank $1^{\text {Ity } 16 / i t y 16}$ mutant. To further demonstrate the importance of Hamp during Salmonella infection, we did challenge Hamp knockout mice with Salmonella Typhimurium (Fig. 6E). We showed that mice deficient for $\operatorname{Hamp}\left(\operatorname{Hamp}^{-\prime-}\right)$ were significantly more susceptible to infection than mice carrying one $\left(\right.$ Hamp $\left.^{+/-}\right)$or two $\left(\right.$Hamp $\left.^{+/+}\right)($Mantel-Cox test $\mathrm{P}=0.0079)$ wild type allele at Hamp. These results confirm the importance of Hamp during acute systemic model of Salmonella Typhimurium infection.

\section{Salmonella Susceptibility in Ank $1^{+/ l t y 16}$ Heterozygous Mice is Associated with Low Levels of Hamp and Iron Accumulation in Tissues}

Ank1 $1^{+/ I t y 6}$ heterozygous mice present an intermediate phenotype with respect to susceptibility to infection (survival) when compared to $A n k 1^{+/+}$and $A n k 1^{1 \text { ty } 16 / \text { Ity } 16}$ littermates (Fig. 1E). Clinically, Ank $1^{+/ \text {Ity16 }}$ mice did not present any sign of anemia (Table 1) or splenomegaly (Fig. 2C). However, we did observe a small but significant increase in the number of RBCs (Fig. 8A). In addition, the $A n k 1^{+/ I t y 16}$ mice presented moderate extramedullary hematopoiesis in the spleen (Fig. S1) and lower levels of Hamp expression in the liver (Fig. 8B) and kidneys (Fig. 8C) that was paralleled by increased expression of $G d f 15$ (data not shown). 

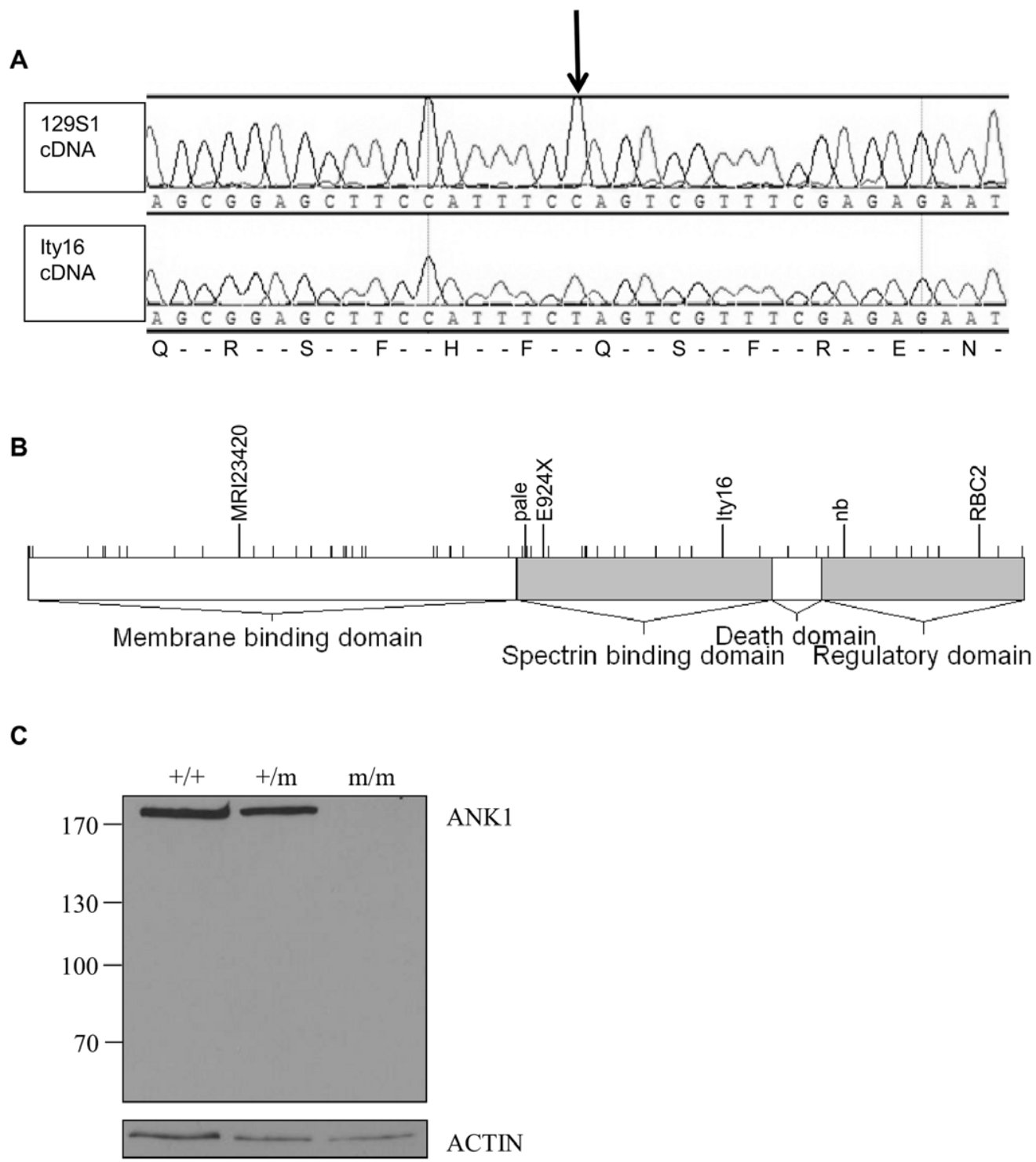

Figure 3. Ity16 mutant mice carry mutation within the Ank1 gene. A) A C to T transition (arrow) at CDNA position 4069 (c.4069C $>$ T) resulting in a stop codon at amino acid position 1357 (p.Gln1357Ter) was detected in Ank $1^{1 \text { ty } 16 / \text { thy } 16}$ mutant. The Ity 16 mutation is located in exon 33 using the exon numbering of the Ank1 transcript ID ENSMUST00000121802 (Ensembl build 37). B) Schematic representation of the different domains of ANK1 (adapted from [57]) and location of mutations previously identified in human (small ticks) [18] and mouse ANK1 [13,14,15,16,17]. The Ity16 allele is shown together with two spontaneous ANK1 recessive mutations ( $n b$ and pale) and three dominant mutants (RBC2, M1Wlst and MRI23420). C) Immunoblot of RBC ghosts prepared from wild-type $(+/+)$, heterozygous $(+/ \mathrm{m})$ and mutant Ank1 $(\mathrm{m} / \mathrm{m})$ littermates probes with ANK1 antibody. The size of the molecular markers in kDa are shown on the left. An expected band of about $210 \mathrm{kDa}$ was observed in samples from the wild-type and heterozygous mice while this band or any smaller bands corresponding to a truncated version of the protein could not be detected in mutant mice. doi:10.1371/journal.pone.0055331.g003

Early during infection (day 2), Ank $1^{+/ \mathbf{I t y} \mathbf{1 6}}$ mice behaved as wild type littermates for most subphenotypes we have measured including different blood parameters (Table 1) and organ CFUs (Fig. 4). To understand the pathophysiology of the underlying susceptibility of $A n k 1^{+/ I t y 16}$ mice, we followed the animals for a longer period of time during infection. At day 6 post infection when the animals become clinically diseased, Ank $1^{+/ I t y 16}$ mice presented consistent increase in bacterial load in the spleen, liver and kidney with a significant difference detected in the kidney (Fig. 8D). At day 6 post infection, iron pigment deposition was detected in the liver and kidneys of $A n k 1^{+/ 1 t y 16}$ mice and not in wild type littermates (Fig. S3). The increase in kidney bacterial load together with iron deposition following infection clearly induced a local inflammatory response that is reflected by higher expression of renal $I l 1$ (Fig. 8E) and Il6 (Fig. 8F) mRNA levels by a factor of 2.5 fold compared to wild-type controls. During infection, both wild-type and $A n k 1^{+/ \text {Ity } 16}$ heterozygous mice developed a mild anemia although the $A n k I^{+/ \text {Ity } 16}$ heterozygous mice still presented higher RBC counts compared to control mice (Fig. 8A). The higher red cell mass present in Ank1 /Ity16 heterozygous mice during infection could be explained by increased Epo expression by the kidneys (Fig. 8G). During infection, liver Hamp expression levels were not significantly modulated in both wild-type mice and $A n k I^{+/ \text {Ity } 16}$ heterozygous mice (Fig. 8B) although we did observe a modest but significant increase in kidney Hamp expression in $A n k 1^{+/ \text {Ity } 16}$ mice later 
A

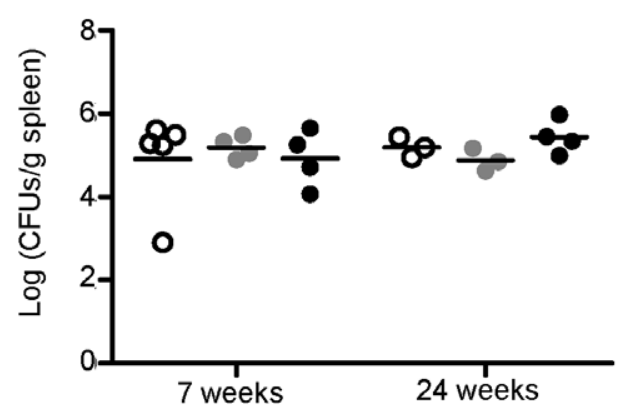

C

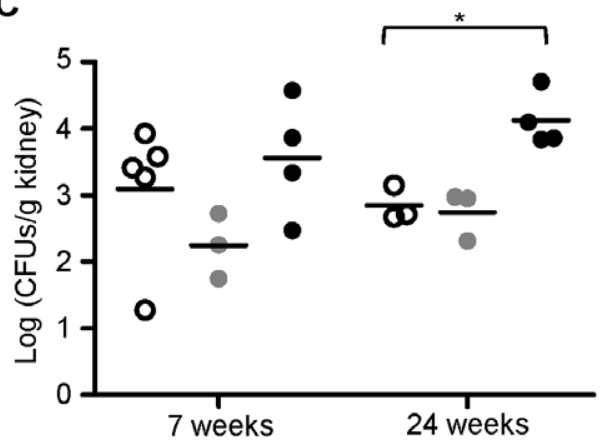

D

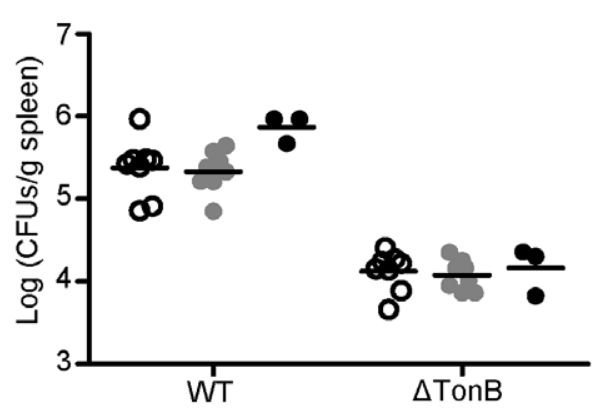

B

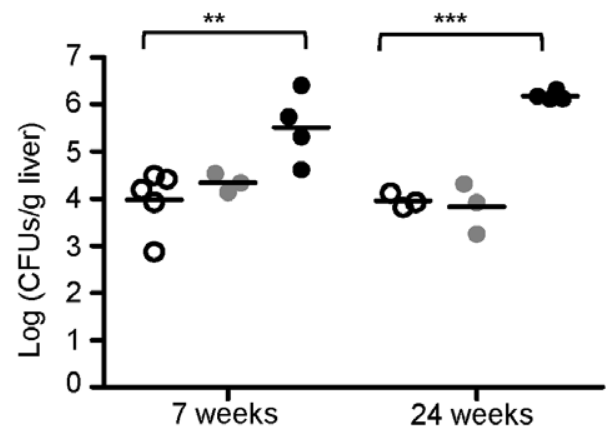

E

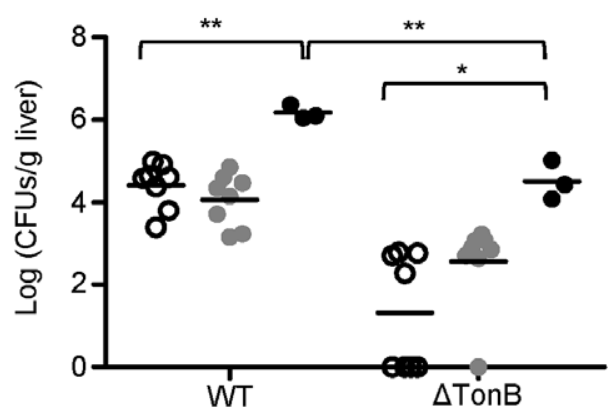

Figure 4. Bacterial load in spleen, liver and kidney after infection with Salmonella Typhimurium in Ity16 mutant, heterozygous and wild type mice. The bacterial load was measured 2 days after infection in the spleen (A), liver (B), and kidney (C) of wild type aged 7 weeks (open circle), and 24 weeks (open circle), heterozygous mice at 7 weeks (gray circle) and 24 weeks (gray circle) and Ity 16 mutant mice at 7 weeks (filled circle) and 24 weeks (filled circle) ( $n=3-5$ per genotype and age). Ity 16 mutant mice present higher bacterial load in the liver and kidneys compared to heterozygous and wild type littermates. Bacterial load of Salmonella Typhimurium and AtonB Salmonella Typhimurium was measured 2 days after infection in spleen (D) and liver (E) of wild type (open circle), heterozygous (gray circle) and lty16 (black circle) mice aged 7-12 weeks ( $\mathrm{n}=3-8$ per genotype). Results are representative of at least two experiments. An * represents a P-value of less 0.05 ; **represents a P-value of less than 0.001 ; ***represents a P-value of less than 0.0001 .

doi:10.1371/journal.pone.0055331.g004

during infection (Fig. 8C). To test the involvement of Hamp in the susceptibility phenotype of $A n k 1^{+/ \text {Ity } 16}$ heterozygous mice, we treated the mice with HAMP peptide. Ank $1^{+/ 1 t y 16}$ heterozygous mice treated with HAMP peptide showed significant survival benefits (Log Rank (Mantel-Cox) test $\mathrm{p}=0.008$ ) compared to heterozygous mice treated with PBS confirming the importance of HAMP in the host response to Salmonella infection (Fig. $8 \mathrm{H}$ ).

\section{Discussion}

We report here the identification of a novel mutation (Ity 16) in the gene Ank1 identified in an ENU recessive screen for susceptibility to typhoid-like disease in mice. The mutation consists in a nonsense mutation (p.Gln1357Ter) located in the spectrin binding domain of Ankl. ANK1 protein was not detected in RBC ghosts suggesting that $A n k 1^{I t y 16}$ is a null allele although we could not exclude the possibility that low levels of other ANK1 isoforms lacking the N-terminal region may remain undetected. Mice carrying the homozygous allele for Ank1 $1^{I t y 16}$ present clinicopathological features of human hereditary spherocytosis (HS) which is the most common cause of inherited chronic hemolysis in Europe and North America with a prevalence in population of 1 in 2000 [31,32]. Clinical manifestations of the human disease range from mild subclinical to severe lifethreatening [12]. HS is characterized by spherocytic erythrocytes, splenomegaly, hyperbilirubinemia, thrombosis, leukocytosis and cardiac hypertrophy [19] and is predominantly caused by mutations in one of the erythroid membrane cytoskeleton components including ANK1, Band 3 (SLC4A1), $\alpha$-spectrin (SPNA), $\beta$-spectrin (SPNB), and protein 4.2 (EBP4.2) [12]. 

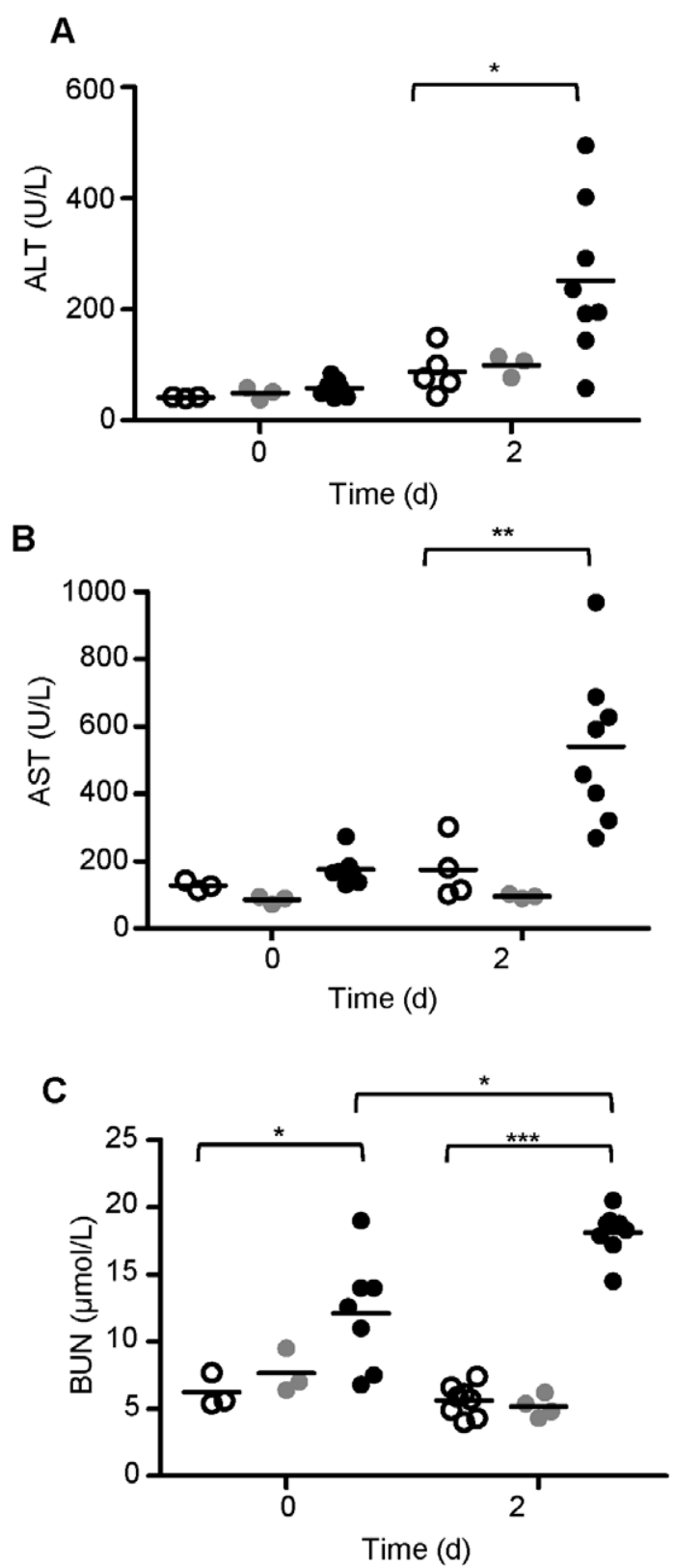

Figure 5. Ity16 mutant mice present elevated blood urea nitrogen (BUN), alanine transaminase (ALT) and asparatate transaminase (AST) during Salmonella infection. BUN (A), ALT (B) and AST (B) levels were measured at day 0 (prior to infection) and day 2 post infection in 7 week old $A n k 1^{+/+}$wild type, $A n k 1^{+/ l t y 16}$ heterozygous and $A n k 7^{1 t y 16 / t y 16}$ mutant mice. The values for each individual mouse are shown ( $n=3-8$ per genotype). Wild type mice are represented by open circles, heterozygous by gray circles and Ity 16 mutant by black circles. The high levels of BUN levels detected in mutant mice at day 0 most probably reflect the nephrotoxicity of iron accumulation in the kidney. During infection BUN, ALT and AST levels increased in mutant mice denoting kidney and liver damage. An *represents a P-value of less than 0.05 ; *** represents a P-value of less than 0.0001 .

doi:10.1371/journal.pone.0055331.g005

Mutations in the $A \mathcal{N} K 1$ gene accounts for about $50 \%$ of genetically defined cases of HS and most cases of HS associated with ANK1 mutations [19] $(>80 \%)$ show a dominant mode of inheritance [12]. In HS and in mice lacking ANK1, the consequence of the ineffective erythropoiesis, extramedullary hematopoiesis and re- tention of abnormal RBC is splenomegaly and tissue iron overload leading to oxidative damage and cardiac failure (reviewed in [33]).

In addition to the mutation described in the current paper, five mutations within the Ankl locus have been reported (Fig. 3B). Two of them were spontaneous recessive mutations $\left(A n k 1^{n b}\right.$ and Ank $1^{\text {pale }}$ ), two additional one were identified in dominant ENU screens for blood cell phenotypes $\left(A n k 1^{R B C 2}\right.$ and $\left.A n k 1^{E 924 X}\right)$ and the last one, in a dominant screen for resistance to malaria in SJL/J mice $\left(A n k 1^{M R I 23420}[13,14,15,16,17]\right.$. Mice carrying the Ity 16, $n b$, $R B C 2, E 924 X$ or MRI23420 allele at Ank1 present characteristic clinicopathological features of HS including severe anemia, reticulocytosis, splenomegaly with complete effacement of the normal splenic architecture, multiorgan iron overload and low body weight. Embryonic and neonatal lethality is observed and may vary according to the genetic background and the position of the mutation $\left([14,15]\right.$ and current paper). Ank1 $1^{1 \text { ty } 16 / 1 y 16}$ mutants are on a mixed DBA/2J X 129/S1 background and most homozygous are viable $(18 \%$; the expected ratio is $25 \%)$ and survive to at least 6 months of age. In mutant Ank1 mice where there is $100 \%$ neonatal mortality, the death was associated with severe clinical signs of jaundice due to massive hemolysis [17].

The severity of anemia in Ank $1^{\text {Ity } 16 / \text { Ity } 16}$ mutant mice and other ENU-induced $A n k 1$ mutants $\left(A n k 1^{R B C 2}\right.$ and $\left.A n k 1^{E 924 X}\right)$ was similar with hematocrit levels varying between $22-27 \%$. Reticulocytosis was present in all mutants and significantly different from control mice. Ank $1^{I_{\text {ty } 16 / I t y 16}}$ mutant mice exhibit extensive iron accumulation in several organs including the kidneys, a pathological observation that was not reported in other Ank1 mutants $[13,14,15,16]$. A normal iron balance in the host is required for adequate innate and adaptive immune responses. This is well illustrated by the observation that both iron overload and iron depletion impaired the host immune response in humans and in animal models of infections [5,6,9,34]. Iron overload is known to influence the course of infection by favoring microbial replication and also by affecting antimicrobial immune effector mechanisms. Iron overload has several consequences on the immune system including decreased capacity of macrophage to phagocytose, reduced neutrophil migration, modifications of $\mathrm{T}$-cell subsets, suppression of the complement system, and increased oxidative stress leading to tissue damage [35]. Additionally, acute iron depletion in mice increased their susceptibility to Salmonella infection because of impaired NADPH-dependent respiratory burst activity [36]. In the current study, we present several evidences showing that iron overload is an important mechanism in influencing bacterial load including the concomitant presence of iron overload and high bacterial burden in liver and kidneys and the observation that Salmonella strain deficient in iron uptake grows better in the iron rich environment of $A n k 1^{\text {Ity } 16 / I_{\text {Iy }} 16}$ liver. We do also show that in heterozygous $A n k 1^{+/ I y y 16}$ mice, higher bacterial load is detected only in tissues where iron accumulation is detected. These results clearly show the importance of iron overload in susceptibility to Salmonella infection in Ank1 $1^{\text {Ity } 16 / \text { Ity } 16}$ and $A n k 1^{+/ I y y 16}$ mice.

In Ank1 mutant mice and HS patients, the normal life span of erythrocytes in the peripheral blood is substantially shortened and retention of abnormal erythrocytes by the spleen was shown to be the dominant mechanism for their reduced life-span $[12,14]$. Hemolysis of erythrocytes results in the liberation of heme which induces the expression of Hmox 1 . HMOXl catalyzes the degradation of heme to carbon monoxide, biliverdin that is converted to bilirubin and ferrous iron [37]. In Ank1 $1^{\text {Ity } 16 / \text { It } y 16}$ mutant mice, we observed high serum bilirubin levels and iron overload in the liver and the kidneys but not in the spleen. High Hmox 1 mRNA levels was observed in the liver and the kidneys but 
A

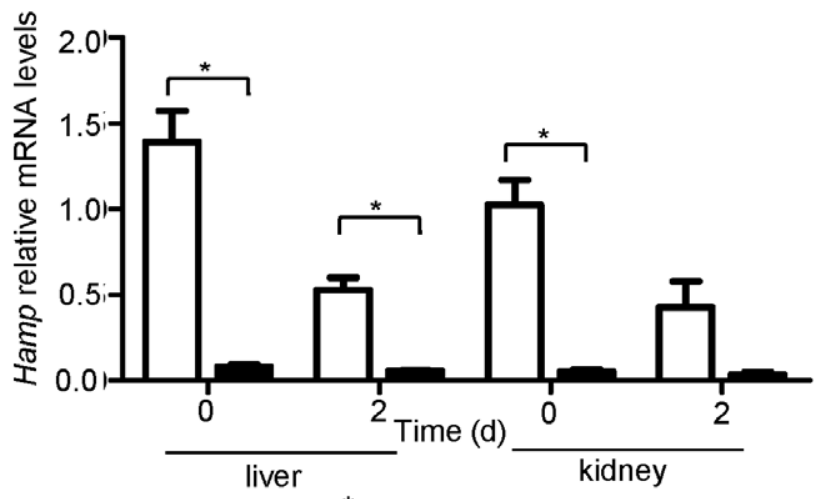

B

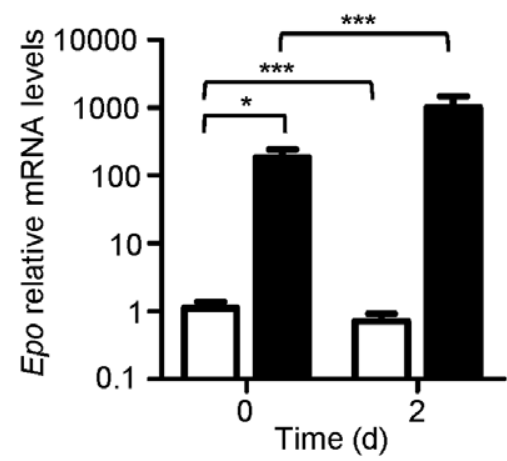

C

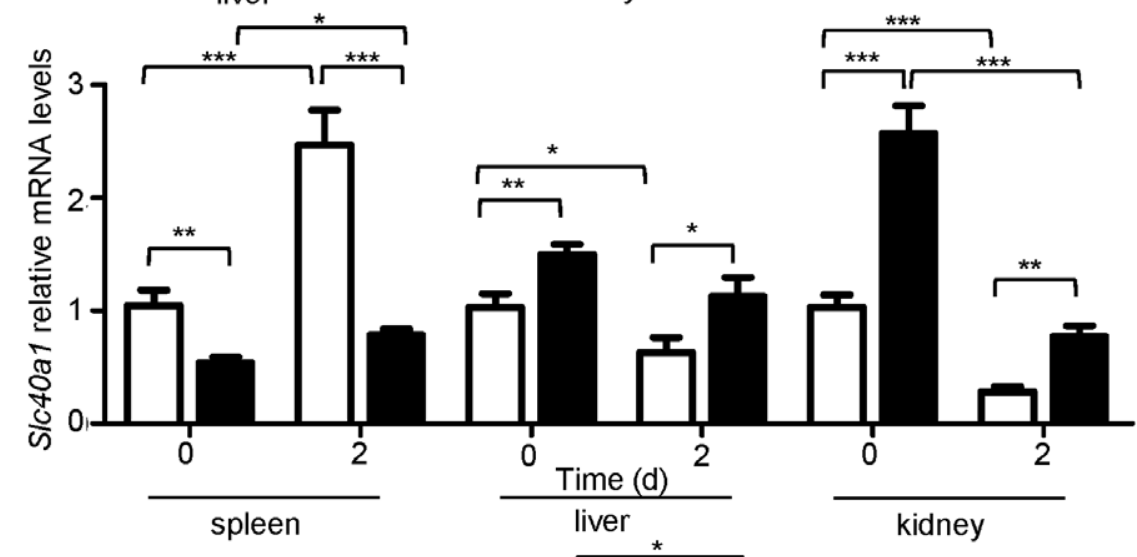

D

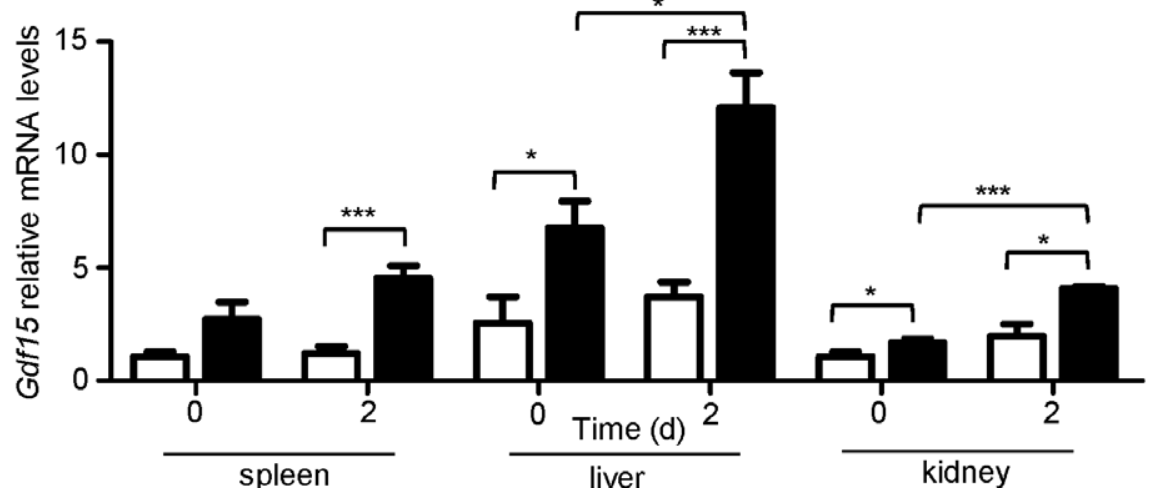

E

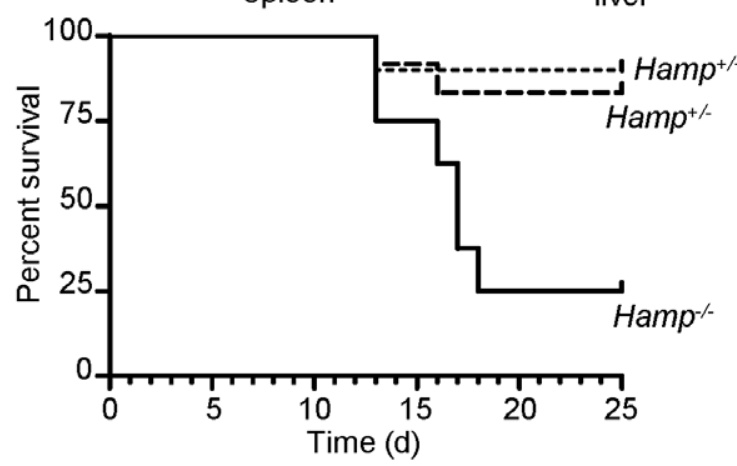

Figure 6. Tissue expression of genes involved in iron metabolism in 7 week old $A n k 1^{+/+}$wild type and $A n k 1^{1 t y 16 / t y 16}$ mutant mice. Real-time PCR expression of liver Hamp (A), kidney Epo (B), spleen, liver and kidney S/c40a1 (C), and spleen and liver Gdf15 (D). The relative mRNA levels at day 0 and day 2 post infection are shown in $A n k 1^{1 /+}$ wild type (clear bar, $\mathrm{n}=3$ ) and $A n k 1^{\text {ty } 16 / t y 16}$ mutant $(\mathrm{black}$ bar, $\mathrm{n}=3)$ mice. Epo mRNA

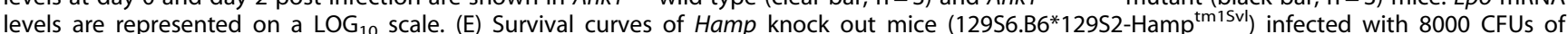
Salmonella Typhimurium. Solid line represents homozygous $\mathrm{Hamp}^{-1-}$ knock out $(\mathrm{n}=8)$, dashed line represents heterozygous $\mathrm{Hamp}^{+/-}(\mathrm{n}=12)$, and dotted line represents homozygous wildtype Hamp ${ }^{+/+}$alleles $(n=10)$. Log-Rank (Mantel-Cox) for Hamp ${ }^{+/+}$and Hamp ${ }^{-/-} p=0.0071$. An ${ }^{*}$ represents a P-value of less than $0.05 ; * *$ represents a P-value of less than $0.001 ;{ }^{* * *}$ represents a P-value of less than 0.0001.

doi:10.1371/journal.pone.0055331.g006 
A

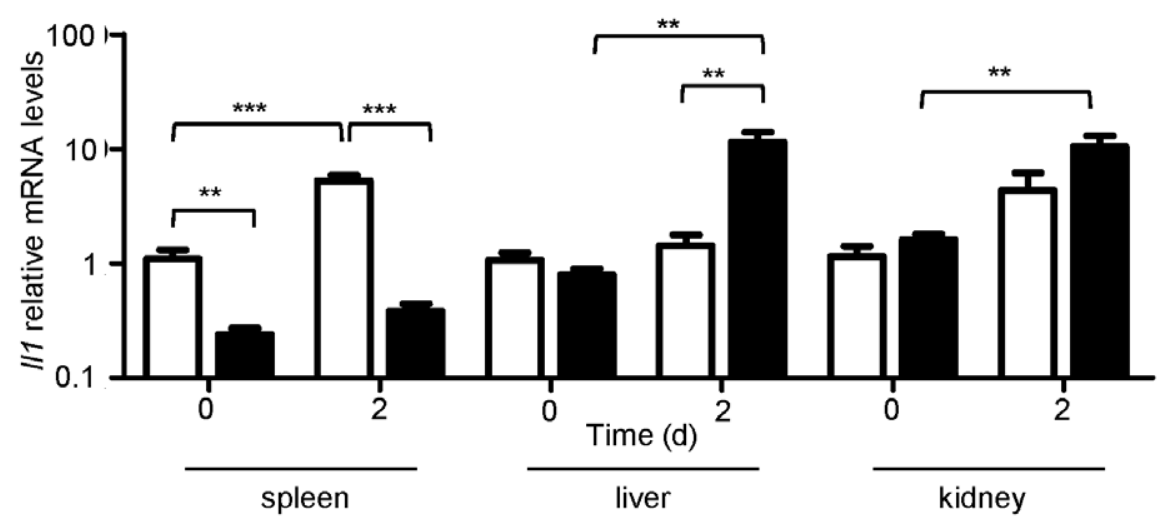

B

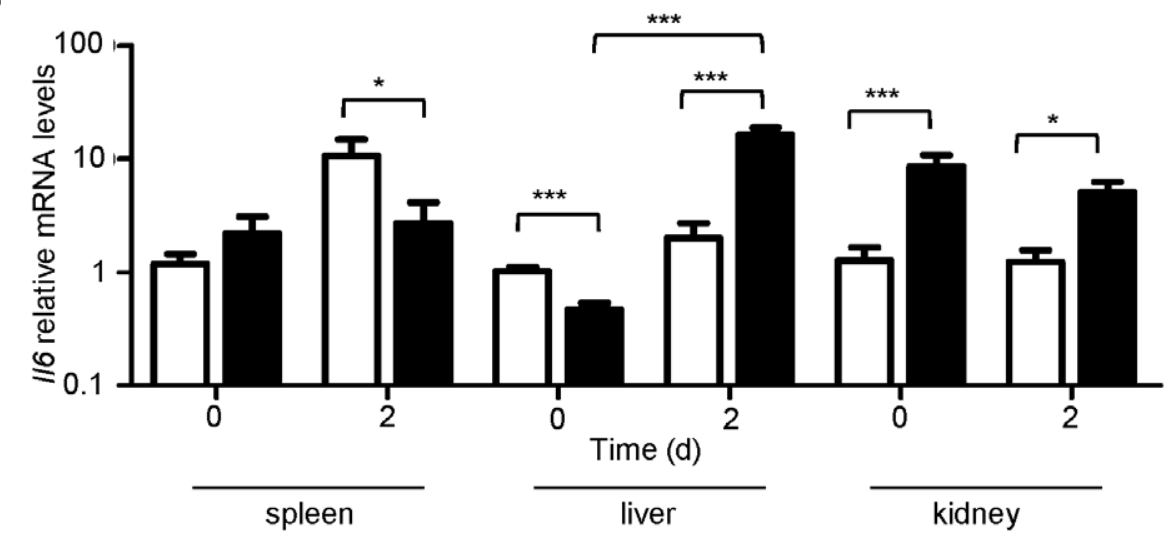

C

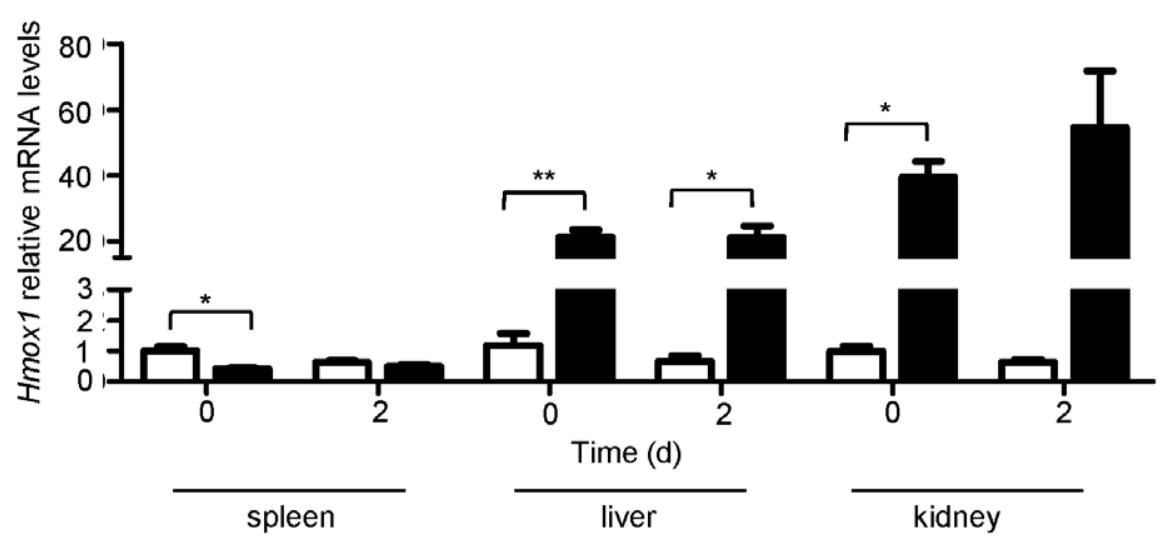

Figure 7. Cytokine profiles in 7 week-old $A n k 1^{+/+}$wild type and $A n k 1^{\prime t y 16 / I t y 16}$ mutant mice during infection with Salmonella Typhimurium. Relative spleen, liver and kidney mRNA levels are shown for $/ / 1(\mathrm{~A}), / / 6(\mathrm{~B})$, and $H$ mox 1 (C) at day 0 and day 2 post infection. Ank $1^{+/+}$ wild type mice $(n=3)$ are represented by clear bar and Ank $1^{\text {tty } 16 / 1 t y 16}$ mutant mice $(n=3)$ by a black bar. All values are compared to wild type mRNA levels at day 0 and presented on a $\mathrm{LOG}_{10}$ scale. An ${ }^{*}$ represents a P-value of less than $0.05 ;{ }^{*}$ represents a P-value of less than $0.001 ;{ }^{* *}$ represents a P-value of less than 0.0001 .

doi:10.1371/journal.pone.0055331.g007

not in the spleen of mutant mice suggesting that the iron overload present in the liver and kidneys resulted from degradation of heme by Hmox 1. Low levels of Hmox 1 in the spleen of mutant mice are most likely a consequence of splenic macrophage depletion (data not shown) and could explain the observation that there is no iron deposition in the spleen of mutant mice and less bacterial growth considering that hemophagocytic macrophages may provide a survival niche for Salmonella [38]. Of particular interest, increased levels of Hmox 1 has been recently shown to impair resistance to Salmonella infection in a context of hemolysis through the suppression of the oxidative burst capacity of neutrophils [39], 
A

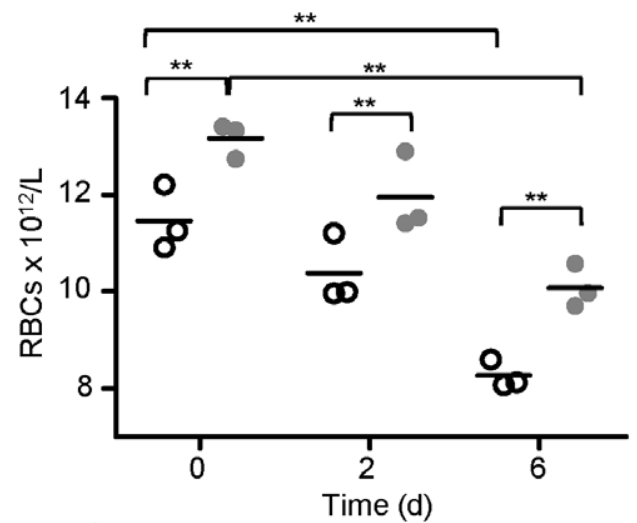

C

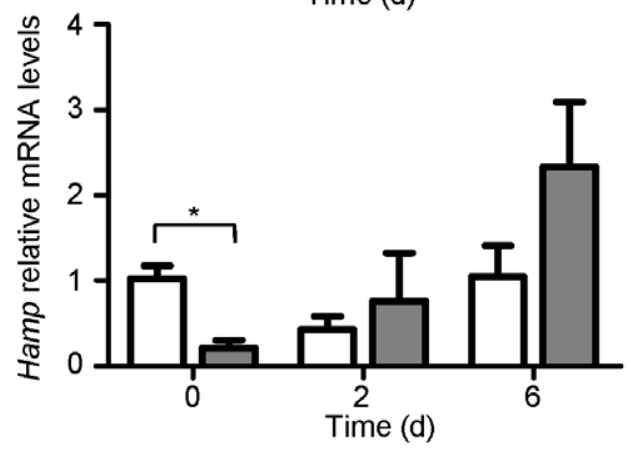

E

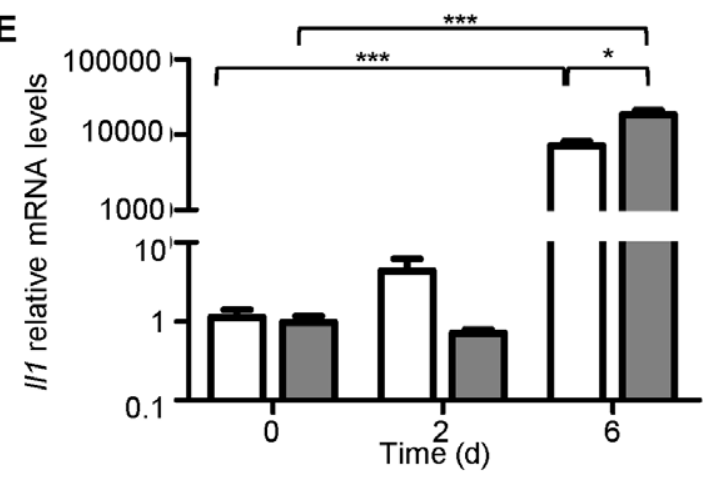

G

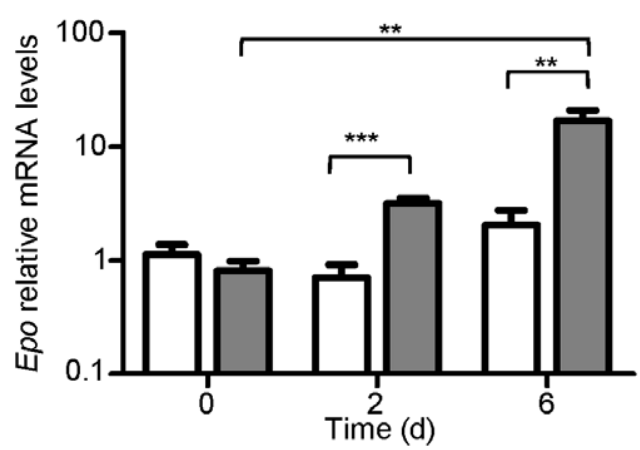

B

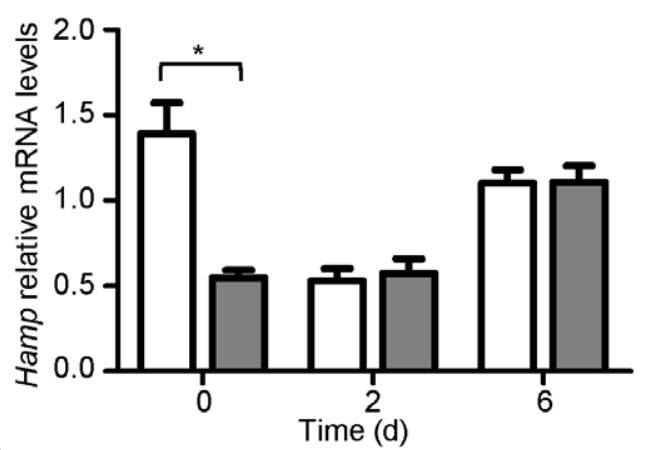

D
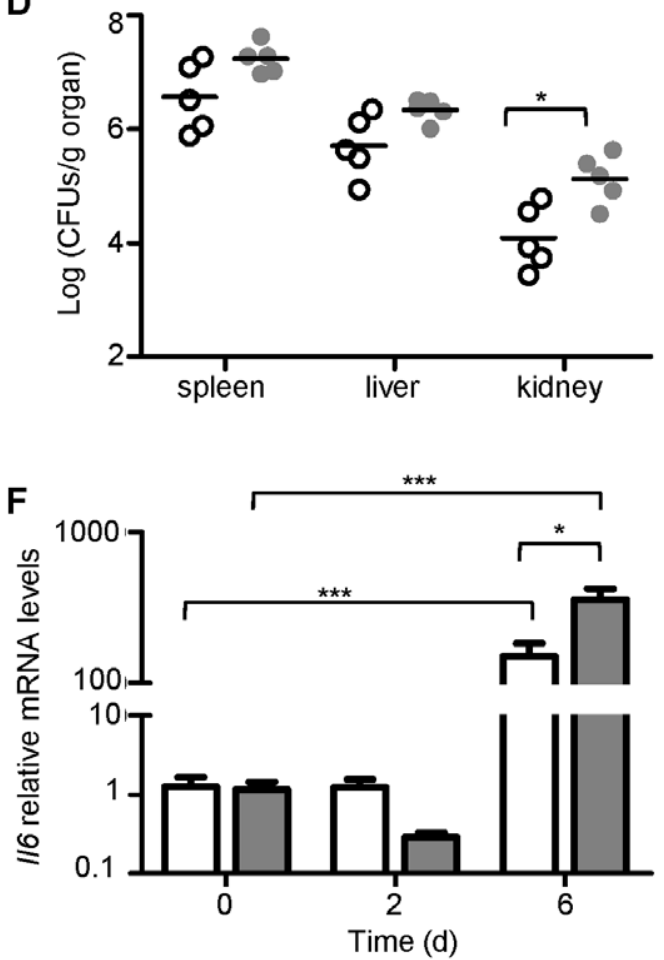

H

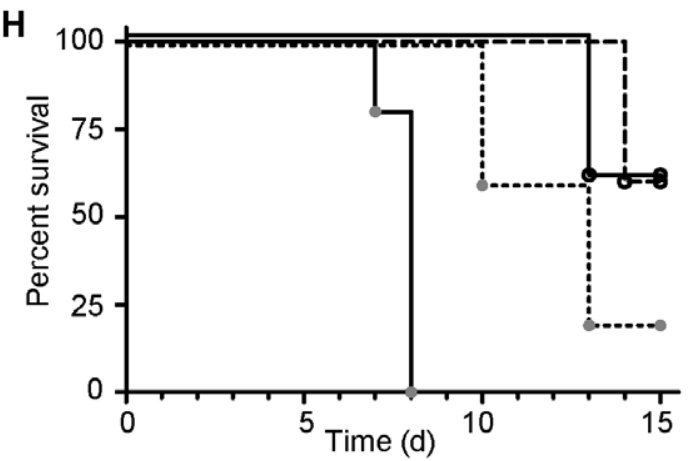

Figure 8. Characterization of $\boldsymbol{A n k} \boldsymbol{1}^{+/ 1 t y 16}$ heterozygous mice. RBC counts (A) and bacterial burden in spleen, liver and kidney (D) were measured in 7 week old $A n k 1^{+/+}$wild type and $A n k 1^{+/ t y 16}$ heterozygous mice at day 0 (prior infection), day 2 and day 6 post infection. Wild type $A n k 1^{+/+}$mice are represented by clear circles and $A n k 1^{+/ l t y} 16$ heterozygous mice by gray circles. Relative kidney mRNA levels are shown for Hamp (C), II1 (E), IL6 (F) and Epo (G) at day 0, day 2 and day 6 post infection. (B) Relative liver Hamp levels at day 0, day 2 and day 6 post infection. Wild type $A n k 1^{+/+}$mice are represented by clear bars ( $\mathrm{n}=3$ for day 0 and day $2 ; \mathrm{n}=4$ for day 6 ) and Ank $1^{+/ l t y 16}$ heterozygous mice by gray bars ( $\mathrm{n}=3$ for day 0 and day $2 ; n=4$ for day 6$)$. (H) Survival curves of $A n k 1^{+/+}$wild type $\left(n=5\right.$; open circle) and Ank $1^{+/ l t y 16}$ heterozygous ( $\mathrm{n}=5$; gray circle) mice with ( $n=5$; dashed or dotted line) or without ( $n=5$; solid line) HAMP treatment infected with 5000 CFUs of Salmonella Typhimurium. Log-Rank (MantelCox) for $A n k 1^{+/ l t y 16}$ heterozygous with and without HAMP treatment $\mathrm{p}=0.008$. The experiment was repeated twice. An * represents a P-value of less than $0.05 ;{ }^{* *}$ represents a P-value of less than $0.001 ;{ }^{* * *}$ represents a P-value of less than 0.0001 .

doi:10.1371/journal.pone.0055331.g008 
suggesting that high Hmox1 levels in Ank1 $1^{\text {Ity } 16 / \text { Ity } 16}$ mutant mice may contribute to their susceptibility.

It has been shown that the kidney plays an important role in iron metabolism. It has also been reported that a significant amount of serum iron is filtered by the glomeruli and is reabsorbed [40]. In Ank $1^{\text {Ity } 16 / \text { Ity } 16}$ mutant mice, the excessive iron load in the kidneys most likely results from the high rate of hemoglobin filtration and reabsorption by renal tubular cells. Iron deposition in glomeruli, and proximal and distal tubules of the kidney has been observed in chronic experimental hemosiderosis [41]. With aging, Ank $1^{\text {Ity 16/Ity } 16}$ mutants develop a more severe nephropathy compared to heterozygous and wild type animals and are more susceptible to infection as measured by increased in bacterial proliferation upon infection. The higher degree of iron accumulation in liver and kidneys in older animals is most likely responsible for these observations.

Another hallmark of ineffective erythropoiesis in Ank $1^{\text {Ity } 16 / \text { Ity } 16}$ mutant mice is an increase in Epo and Gdf15 levels associated with suppression of Hamp expression. Hamp expression is known to be regulated by intestinal iron absorption, iron recycling by macrophages and iron mobilization from hepatic stores by inhibiting iron export through its binding to Slc40a1 causing its internalization [42]. In Ank1 1ty16/Ity 16 mice, low Hamp expression had a modest impact on the expression of Slc40a1 in the liver. The synthesis of Hamp is also upregulated in hepatocytes by inflammatory cytokines and inhibited by anemia, hypoxia and erythropoietic activity $[43,44]$. As a consequence of anemia and in response to tissue hypoxia, increased expression of Epo is detected in the kidneys. Despite these changes to compensate for erythrocyte demand, erythropoisesis is not efficient and led to massive expansion of the erythroid compartment. GDF15 is a member of the TGF $\beta$ superfamily that was shown to negatively regulate the expression of Hamp in vitro $[45,46]$. In fact, upregulation of GDF15 and suppression of HAMP have been observed in $\beta$-Thalassemia and it is thought that erythroid expansion influences the regulation of HAMP expression through systemic release of GDF15 from erythroblasts [30,47]. Low levels of Hamp in response to ineffective erythropoiesis, as observed in Ank $1^{\text {It } 16 /}$ ${ }_{1 t y} 16$ mutant mice, clearly exacerbate extramedullary erythropoiesis, tissue iron deposition and splenomegaly. During infection, liver Hamp expression levels remain suppressed and Gdf15, Il1 and Il6 expression increased significantly in $A n k 1^{1 \text { ty } 16 / \text { Ibl16 }}$ mutant mice compared to wild type littermates. Gdf15 has been shown to be highly expressed in macrophages stimulated with LPS and to be modulated by several cytokines including IL-1 [48] and by intracellular iron depletion in vitro [49]. The high Gdf15 expression observed during infection in Ank $1^{\text {Ity } 16 / \text { Ity } 16}$ mutant mice could be explained by the progression of anemia and expansion of the erythroid compartment, by the high expression of cytokines induced by infection with Salmonella or as a consequence of intracellular iron deprivation due to low levels of Hamp expression.

Salmonella susceptibility in Ank1 $1^{1 \text { ty } 16 / \text { Ity } 16}$ differs from that observed in the iron overload disorder, hereditary hemochromoatosis (HFE). Hfe-deficient mice do not lack Hamp, present excessive accumulation of iron in the liver and improve resistance to Salmonella infection [50]. In Hfe-deficient mice, high lipocalin-2 (Lcn2) levels were observed in the liver and the spleen prior infection and increased resistance to infection in these mice was associated with higher induction of $L c n 2$ expression that was shown to reduce the availability of iron for Salmonella within macrophages [50]. In Ank1 $1^{\text {Ity 16/Ity16 }}$ mutant mice, the spleen and liver expression of $L c n 2$ did not differ from that observed in littermate controls prior infection however we did observe a significant increased in the spleen and liver expression of $L c n 2$ during infection (data not shown). There were no significant differences between genotypes in the spleen in contrast levels of $L c n 2$ were significantly higher (by a factor of 1.5 LOG) in the liver of Ank $1^{\text {Ity } 16 / \text { Ity } 16}$ mutant mice compared to littermate controls and parallel the high bacterial loads detected in this organ. Altogether, these data suggest that high levels of $\operatorname{Lcn} 2$ expression in a context of low Hamp expression do not protect Ank1 $1^{1 \text { yy } 16 / \text { Ity } 16}$ mutant mice from systemic Salmonella infection.

Of particular interest was the intermediate susceptibility of Ank $1^{+/ 1 t y 16}$ mice to infection with Salmonella Typhimurium. In heterozygous mice, there is only one functional copy of $A n k 1$ which may be limiting to confer a normal structure to the RBC membrane and cause a partial loss of membrane surface. Although the half-life of RBC appears not to be affected in $A n k 1^{+/ 1 t y 16}$ mice, small increase in osmotic fragility has been reported which may lead to more RBC destruction by the spleen [14]. In fact, we did observe an increase in extramedullary erythropoiesis in the spleen of $A n k 1^{+/ 1 t y 16}$ mice although the mice were not anemic. The phenotype observed in $A n k I^{+/ I t y 16}$ mice may correspond to the human mild form of HS where patients have compensated hemolysis without anemia. As observed in uninfected $A n k 1^{1 \text { ty } 16 / \text { Ity } 16}$ homozygous mice, liver and kidneys Hamp levels were low compared to controls and levels of Gdf15 were increased. Hamp is mainly produced by the liver but it has been found also to be highly expressed in the apical pole of epithelial cells of distal tubules and collecting ducts of the kidney [29,51]. In humans, diminished serum hepcidin concentration has been observed in human erythroid pathologies where there is no anemia but an increased in red cell mass as seen in primary polycythemia [52]. In Ank $1^{+/ 1 t y 16}$ mice, the Salmonella susceptible phenotype appears to be expressed predominantly in the kidney where we found significant accumulation of iron and bacteria. Low levels of Hamp expression in $A n k 1^{+/ I t y 16}$ heterozygous mice at the time of infection appears to contribute to iron accumulation in the kidney and liver and consequently favor bacterial growth. The central role of Hamp in the host response to Salmonella infection was validated using mice deficient for Hamp. These mice are not anemic and present an important iron overload secondary to low level of Hamp a phenotype similar to the one observed in heterozygous mice [21] and are highly susceptible to Salmonella infection (current paper). Finally, direct evidence of the role of Hamp in the host response to Salmonella infection was obtained by treating $A n k 1^{+/ I t y 16}$ mice with hepcidin. Hepcidin treatment did not improve resistance of $A n k 1^{1 t y 6 / 1 t y 16}$ mutant mice where iron accumulation in tissues is massive however it was clearly beneficial in $A n k 1^{+/ 1 t y 16}$ heterozygous mice. We do not know at the moment the exact mechanism of how hepcidin is improving resistance to infection in $A n k 1^{+/ 1 t y 16}$ heterozygous mice. Induction of hepcidin through transgenesis in mouse models of hemochromatosis and $\beta$ Thalassemia was shown to alter the pattern of cellular iron accumulation and limit iron overload [53,54]. In addition, administration of an hepcidin agonist in Hamp ${ }^{-1-}$ mice caused a partial redistribution of iron from the liver to the spleen [55]. An antimicrobial effect of hepcidin could be also considered although the impact of hepcidin on bacterial growth has been shown only in vitro [56].

Overall, the current study shows that the suppression of Hamp expression and iron overload contribute to the susceptibility of Ank $1^{\text {Ity } 16 / \text { Ity } 16}$ mutant and $A n k 1^{+/ \text {Ity } 16}$ heterozygous mice to Salmonella infection. This emphasizes the importance of iron metabolism and a role for Hamp in susceptibility to systemic Salmonella infection. 


\section{Supporting Information}

Figure S1 Histopathologic examination of the spleen, liver and kidney of 7 week old $A N K 1^{+/+}$wild type, $A N K 1^{+/ I t y 16}$ heterozygous, and $A N K 1^{\text {Ity16/Ity16 }}$ mutant mice before infection (day 0 ). H\&E stain of uninfected spleen of wild type (A), heterozygous (E), and Ity16 mutants (I). Prussian blue stain of uninfected spleen, liver and kidney, respectively, of wild type $(\mathrm{B}, \mathrm{G}, \mathrm{D})$, heterozygous $(\mathrm{F}, \mathrm{G}, \mathrm{H})$, and Ityl6 mutants $(\mathrm{J}, \mathrm{K}, \mathrm{L})$. All pictures are taken at $200 \times$ magnification. $\mathrm{RP}=$ red pulp, $\mathrm{WP}=$ white pulp.

(PDF)

Figure S2 Progression of lesions in kidney and liver 2 days after Salmonella infection of $\mathrm{ANKI}^{+/+}$wild type, $A N K 1^{+/ I t y 16}$ heterozygous, and $A N K 1^{\text {Ity16/Ity16 }}$ mutant mice aged 7 and 24 weeks using hematoxylin \& eosin staining. H\&E stain of uninfected kidney of wild type $(A, B)$, heterozygous $(\mathrm{E}, \mathrm{F})$, and Ity 16 mutants $(\mathrm{I}, \mathrm{J})$ at 7 and 24 weeks of age respectively. $\mathrm{H} \& \mathrm{E}$ stain of day 2 post infection liver of wild type $(\mathrm{C}, \mathrm{D})$, heterozygous $(\mathrm{G}, \mathrm{H})$, and Ity 16 mutants $(\mathrm{K}, \mathrm{L})$ at 7 and 24 weeks of age respectively. All pictures taken at $200 \times$ magnification.

(PDF)

Figure S3 Prussian blue staining of liver and kidney of 7 week old $A N K 1^{+/+}$wild type and $A N K 1^{+/ I t y 16}$ heterozygous mice at day 2 and day 6 post infection with Salmonella Typhimurium. Prussian blue stain of day 2 post infection liver in wild type (A) and heterozygous (D) mice at

\section{References}

1. Mastroeni P, Maskell D (2006) Salmonella infections: clinical, immunological, and molecular aspects. Cambridge, UK; New York: Cambridge University Press.

2. Casanova JL, Fieschi C, Zhang SY, Abel L (2008) Revisiting human primary immunodeficiencies. J Intern Med 264: 115-127.

3. Gordon MA (2008) Salmonella infections in immunocompromised adults. J Infect 56: 413-422.

4. Bustamante J, Zhang SY, von Bernuth H, Abel L, Casanova JL (2008) From infectious diseases to primary immunodeficiencies. Immunol Allergy Clin North Am 28: 235-258, vii.

5. Schaible UE, Kaufmann SH (2004) Iron and microbial infection. Nat Rev Microbiol 2: 946-953.

6. Vento S, Cainelli F, Cesario F (2006) Infections and thalassaemia. Lancet Infect Dis 6: 226-233.

7. Vidal S, Gros P, Skamene E (1995) Natural resistance to infection with intracellular parasites: molecular genetics identifies Nrampl as the Bcg/Ity/Lsh locus. J Leukoc Biol 58: 382-390.

8. Qureshi ST, Lariviere L, Leveque G, Clermont S, Moore KJ, et al. (1999) Endotoxin-tolerant mice have mutations in Toll-like receptor 4 (Tlr4). J Exp Med 189: 615-625.

9. Roy MF, Riendeau N, Bedard C, Helie P, Min-Oo G, et al. (2007) Pyruvate kinase deficiency confers susceptibility to Salmonella typhimurium infection in mice. J Exp Med 204: 2949-2961.

10. Poltorak A, He X, Smirnova I, Liu MY, Van Huffel C, et al. (1998) Defective LPS signaling in $\mathrm{C} 3 \mathrm{H} / \mathrm{HeJ}$ and $\mathrm{C} 57 \mathrm{BL} / 10 \mathrm{ScCr}$ mice: mutations in Tlr4 gene. Science 282: 2085-2088.

11. Rubtsov AM, Lopina OD (2000) Ankyrins. FEBS Lett 482: 1-5.

12. Perrotta S, Gallagher PG, Mohandas N (2008) Hereditary spherocytosis. Lancet 372: 1411-1426.

13. Birkenmeier CS, Gifford EJ, Barker JE (2003) Normoblastosis, a murine model for ankyrin-deficient hemolytic anemia, is caused by a hypomorphic mutation in the erythroid ankyrin gene Ank1. Hematol J 4: 445-449.

14. Rank G, Sutton R, Marshall V, Lundie RJ, Caddy J, et al. (2009) Novel roles for erythroid Ankyrin-1 revealed through an ENU-induced null mouse mutant. Blood 113: 3352-3362.

15. Hughes MR, Anderson N, Maltby S, WongJ, Berberovic Z, et al. (2011) A novel ENU-generated truncation mutation lacking the spectrin-binding and Cterminal regulatory domains of Ank1 models severe hemolytic hereditary spherocytosis. Exp Hematol 39: 305-320 e302.

16. Harris BS, Ward-Bailey PF, Johnson KR, Bronson RT, Reinholdt LG, et al. (2009) A new pale lethal mouse mutation (pale) has been identified on Chromosome 8. MGI Direct Data Submission.
$200 \times$ magnification. Prussian blue stain of day 6 post infection liver of wild type (B) and heterozygous (E) mice at $200 \times$ magnification. Prussian blue stain of day 6 post infection kidney of wild type $(\mathrm{C})$ and heterozygous $(\mathrm{F})$ mice at $1000 \times$ magnification.

(PDF)

Table S1 Primer sequences used for quantitative PGR. Two housekeeping genes: Tbp (TATA box binding protein) and Hprt (hypoxanthine guanine phosphoribosyl transferase) were used. Hepcidin (Hamp), ferroportin (Slc40a1), interleukin 6 (Il6), inteleukin 1 (Ill), interferon gamma (Ifng), erythropoietin (Epo), heme oxygenase 1 (Hmox 1$)$ and growth differentiation factor 15 (Gdf15).

(XLSX)

\section{Acknowledgments}

We are grateful for the excellent technical assistance of Nadia Prud'homme and Line Larivière. We wish to thank Sean Beatty for his help with the analysis of the data, and Pratixa Gandhi from CMARC for the hematology analyses and Jo-Ann Bader and Caroline Therien from the GCRC histology facility for their excellent work.

\section{Author Contributions}

Contributed to the preparation of the paper: MME ER FCH SV SMV. Conceived and designed the experiments: KEY MME ER DM. Performed the experiments: KEY MME ER DC. Analyzed the data: KEY MME ER DC. Contributed reagents/materials/analysis tools: FCH MC MP SMV SV. Wrote the paper: KEY DM.

17. Greth A, Lampkin S, Mayura-Guru P, Rodda F, Drysdale K, et al. (2012) A novel ENU-mutation in ankyrin-1 disrupts malaria parasite maturation in red blood cells of mice. PLoS One 7: e38999.

18. Gallagher PG (2005) Hematologically important mutations: ankyrin variants in hereditary spherocytosis. Blood Cells Mol Dis 35: 345-347.

19. Eber SW, Gonzalez JM, Lux ML, Scarpa AL, Tse WT, et al. (1996) Ankyrin-1 mutations are a major cause of dominant and recessive hereditary spherocytosis. Nat Genet 13: 214-218.

20. Delaunay J (2002) Molecular basis of red cell membrane disorders. Acta Haematol 108: 210-218.

21. Lesbordes-Brion JC, Viatte L, Bennoun M, Lou DQ, Ramey G, et al. (2006) Targeted disruption of the hepcidin 1 gene results in severe hemochromatosis. Blood 108: 1402-1405.

22. Richer E, Prendergast C, Zhang DE, Qureshi ST, Vidal SM, et al. (2010) Nethyl-N-nitrosourea-induced mutation in ubiquitin-specific peptidase 18 causes hyperactivation of IFN-alphass signaling and suppresses STAT4-induced IFNgamma production, resulting in increased susceptibility to Salmonella typhimurium. J Immunol 185: 3593-3601.

23. Boyer E, Bergevin I, Malo D, Gros P, Cellier MF (2002) Acquisition of Mn(II) in addition to $\mathrm{Fe}$ (II) is required for full virulence of Salmonella enterica serovar Typhimurium. Infect Immun 70: 6032-6042.

24. Team RDC (2011) R: A language and environment for statistical computing. Vienna, Austria.

25. Bennett V, Healy J (2008) Organizing the fluid membrane bilayer: diseases linked to spectrin and ankyrin. Trends Mol Med 14: 28-36.

26. Peters LL, Lux SE (1993) Ankyrins: structure and function in normal cells and hereditary spherocytes. Semin Hematol 30: 85-118.

27. Bennett V (1992) Ankyrins. Adaptors between diverse plasma membrane proteins and the cytoplasm. J Biol Chem 267: 8703-8706

28. Veuthey T, D'Anna MC, Roque ME (2008) Role of the kidney in iron homeostasis: renal expression of Prohepcidin, Ferroportin, and DMT1 in anemic mice. Am J Physiol Renal Physiol 295: F1213-1221.

29. Kulaksiz H, Theilig F, Bachmann S, Gehrke SG, Rost D, et al. (2005) The ironregulatory peptide hormone hepcidin: expression and cellular localization in the mammalian kidney. J Endocrinol 184: 361-370.

30. Smith CP, Thevenod F (2009) Iron transport and the kidney. Biochim Biophys Acta 1790: 724-730.

31. Sanchez-Lopez JY, Camacho AL, Magana MT, Ibarra B, Perea FJ (2003) Red cell membrane protein deficiencies in Mexican patients with hereditary spherocytosis. Blood Cells Mol Dis 31: 357-359.

32. Boguslawska DM, Heger E, Chorzalska A, Nierzwicka M, Holojda J, et al. (2004) Hereditary spherocytosis: identification of several HS families with 
ankyrin and band 3 deficiency in a population of southwestern Poland. Ann Hematol 83: 28-33.

33. Gardenghi S, Grady RW, Rivella S (2010) Anemia, ineffective erythropoiesis, and hepcidin: interacting factors in abnormal iron metabolism leading to iron overload in beta-thalassemia. Hematol Oncol Clin North Am 24: 1089-1107.

34. Jones RL, Peterson CM, Grady RW, Kumbaraci T, Cerami A, et al. (1977) Effects of iron chelators and iron overload on Salmonella infection. Nature 267: 63-65.

35. Walker EM Jr, Walker SM (2000) Effects of iron overload on the immune system. Ann Clin Lab Sci 30: 354-365.

36. Collins HL, Kaufmann SH, Schaible UE (2002) Iron chelation via deferoxamine exacerbates experimental salmonellosis via inhibition of the nicotinamide adenine dinucleotide phosphate oxidase-dependent respiratory burst. J Immunol 168: 3458-3463.

37. Kovtunovych G, Eckhaus MA, Ghosh MC, Ollivierre-Wilson H, Rouault TA (2010) Dysfunction of the heme recycling system in heme oxygenase 1-deficient mice: effects on macrophage viability and tissue iron distribution. Blood 116 : 6054-6062.

38. Nix RN, Altschuler SE, Henson PM, Detweiler CS (2007) Hemophagocytic macrophages harbor Salmonella enterica during persistent infection. PLoS Pathog 3: e193.

39. Cunnington AJ, de Souza JB, Walther M, Riley EM (2012) Malaria impairs resistance to Salmonella through heme- and heme oxygenase-dependent dysfunctional granulocyte mobilization. Nat Med 18: 120-127.

40. Wareing M, Ferguson CJ, Green R, Riccardi D, Smith CP (2000) In vivo characterization of renal iron transport in the anaesthetized rat. J Physiol $524 \mathrm{Pt}$ 2: 581-586.

41. Zhou XJ, Laszik Z, Wang XO, Silva FG, Vaziri ND (2000) Association of renal injury with increased oxygen free radical activity and altered nitric oxide metabolism in chronic experimental hemosiderosis. Lab Invest 80: 1905-1914.

42. Nemeth E, Tuttle MS, Powelson J, Vaughn MB, Donovan A, et al. (2004) Hepcidin regulates cellular iron efflux by binding to ferroportin and inducing its internalization. Science 306: 2090-2093.

43. Hentze MW, Muckenthaler MU, Galy B, Camaschella C (2010) Two to tango: regulation of Mammalian iron metabolism. Cell 142: 24-38

44. Ganz T (2011) Hepcidin and iron regulation, 10 years later. Blood 117: 44254433 .
45. Tanno T, Bhanu NV, Oneal PA, Goh SH, Staker P, et al. (2007) High levels of GDF15 in thalassemia suppress expression of the iron regulatory protein hepcidin. Nat Med 13: 1096-1101.

46. Tanno T, Noel P, Miller JL (2010) Growth differentiation factor 15 in erythroid health and disease. Curr Opin Hematol 17: 184-190.

47. Kattamis A, Papassotiriou I, Palaiologou D, Apostolakou F, Galani A, et al (2006) The effects of erythropoetic activity and iron burden on hepcidin expression in patients with thalassemia major. Haematologica 91: 809-812.

48. Bootcov MR, Bauskin AR, Valenzuela SM, Moore AG, Bansal M, et al. (1997) MIC-1, a novel macrophage inhibitory cytokine, is a divergent member of the TGF-beta superfamily. Proc Natl Acad Sci U S A 94: 11514-11519.

49. Lakhal S, Talbot NP, Crosby A, Stoepker C, Townsend AR, et al. (2009) Regulation of growth differentiation factor 15 expression by intracellular iron. Blood 113: 1555-1563.

50. Nairz M, Theurl I, Schroll A, Theurl M, Fritsche G, et al. (2009) Absence of functional $\mathrm{Hfe}$ protects mice from invasive Salmonella enterica serovar Typhimurium infection via induction of lipocalin-2. Blood 114: 3642-3651.

51. Ferguson CJ, Wareing M, Ward DT, Green R, Smith CP, et al. (2001) Cellular localization of divalent metal transporter DMT-1 in rat kidney. Am J Physiol Renal Physiol 280: F803-814.

52. Gordeuk VR, Miasnikova GY, Sergueeva AI, Niu X, Nouraie M, et al, (2011) Chuvash polycythemia VHLR200W mutation is associated with downregulation of hepcidin expression. Blood 118: 5278-5282.

53. Viatte L, Nicolas G, Lou DQ, Bennoun M, Lesbordes-Brion JC, et al. (2006) Chronic hepcidin induction causes hyposideremia and alters the pattern of cellular iron accumulation in hemochromatotic mice. Blood 107: 2952-2958.

54. Gardenghi S, Ramos P, Marongiu MF, Melchiori L, Breda L, et al. (2010) Hepcidin as a therapeutic tool to limit iron overload and improve anemia in beta-thalassemic mice. J Clin Invest 120: 4466-4477.

55. Ramos E, Ruchala P, Goodnough JB, Kautz L, Preza GC, et al. (2012) Minihepcidins prevent iron overload in a hepcidin-deficient mouse model of severe hemochromatosis. Blood 120: 3829-3836.

56. Sow FB, Florence WC, Satoskar AR, Schlesinger LS, Zwilling BS, et al. (2007) Expression and localization of hepcidin in macrophages: a role in host defense against tuberculosis. J Leukoc Biol 82: 934-945.

57. Lux SE, John KM, Bennett V (1990) Analysis of cDNA for human erythrocyte ankyrin indicates a repeated structure with homology to tissue-differentiation and cell-cycle control proteins. Nature 344: 36-42. 